Original Research

\title{
A Highly-efficiency Position Sensorless Electric Vehicle Synchronous Reluctance Motor Drive
}

\author{
Ganisetti Vijay Kumar, Min-Ze Lu, Chang-Ming Liaw *
}

Department of Electrical Engineering, National Tsing Hua University, Hsinchu, Taiwan; E-Mails: vijaykumarganisetti@gmail.com; b10112016@gmail.com; cmliaw@ee.nthu.edu.tw

* Correspondence: Chang-Ming Liaw; E-Mail: cmliaw@ee.nthu.edu.tw

Academic Editors: Marco Bortolini and Francesco Gabriele Galizia

Special Issue: Energy Efficiency in Flexible and Reconfigurable Manufacturing: Emerging Trends, Models and Applications in the Industry 4.0 Era

Journal of Energy and Power Technology

2021, volume 3, issue 3

doi:10.21926/jept.2103037
Received: May 02, 2021

Accepted: July 27, 2021

Published: August 11, 2021

\begin{abstract}
The development of high-efficiency motor drives for various applications is important in the industry 4.0 era, especially for their extensive application to electric vehicles (EVs). In this study, a position sensorless EV synchronous reluctance motor (SynRM) drive has been developed, which exhibits good driving performance and efficiency over a wide speed and load range. To solve the key problems popularly encountered in the existing approaches, the high-frequency injection (HFI) scheme based on q-axis injection has been proposed. In addition, the changed-frequency injection has been adopted considering the effects of speed/load dependent slotting ripple current. Robust observed speed and position controllers have been added to enhance the sensorless control performance. For the SynRM basic driving control scheme, robust current control and adaptive commutation with minimized motor losses have been achieved that yield satisfactory driving performance up to the rated speed and load. Good EV driving performance has been demonstrated experimentally, including starting, dynamic, acceleration/deceleration, and reversible operations. In addition, the steady-state characteristics have been assessed, and the high efficiencies have been observed to be comparable to the standard drive.
\end{abstract}

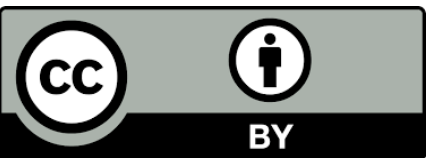

C 2021 by the author. This is an open access article distributed under the conditions of the Creative Commons by Attribution License, which permits unrestricted use, distribution, and reproduction in any medium or format, provided the original work is correctly cited. 


\section{Keywords}

Electric vehicle (EV); synchronous reluctance motor (SynRM); control; sensorless; loss minimization; efficiency

\section{Introduction}

Electric motors [1] are the most popularly employed actuators in the industry. Improvements in their reliability and efficiencies are very important in the internet-of-things (IOT)- based automatic industry 4.0 era. Each type of motor possesses its own critical issues that need to be properly treated for achieving these goals. The synchronous reluctance motor (SynRM) [1-3] is a new type of motor compared to the commonly used induction motor and has high application potential, including EV driving. SynRM possesses two major features: (i) It has a simple and rigid rotor structure without permanent magnets and conductors and thus is suitable for high-speed driving applications; (ii) It has a highly developed torque similar to a series DC motor. However, an adequate commutation instant setting and tuning are recognized as the most challenging issues in obtaining a highefficiency SynRM drive [4, 5]. In particular, the inherent slotting effect [5-9] must also be considered, especially for a sensorless SynRM drive. A few advanced current control approaches $[5,10,11]$ have been developed for achieving better performance considering the nonlinear behavior of SynRM.

For a standard SynRM drive, the absolute position of the rotor is required for implementing the vector control. Nevertheless, in harsh environments, a position sensorless controlled motor drive is preferable. Furthermore, the maloperation due to the failure of the position sensor can be avoided. The approaches developed for the permanent magnet synchronous motors (PMSMs) are also applicable to SynRM with suitable modifications. To date, a large number of position sensorless approaches have been developed, and their surveys can be found in the literature [12-14]. The key bottlenecks in the existing approaches and the future development trends have been commented on in detail [13]. The stable operation of a motor under heavier load and high speed is a key issue that needs to be solved, and accordingly, its successful application to electric vehicle (EV) driving is the major goal that is being pursued. The sensorless control approaches can be generally categorized into (i) observer-based methods, such as adaptive observers [15, 16] and Kalman filter observers [17], (ii) extended back-electromotive force (back-EMF) methods [18-20], and (iii) methods based on rotor saliency [21-27], such as the high-frequency injection (HFI) approach, which is a typical method of this type.

The observed back-EMF-based approaches can only possess satisfactory running characteristics above a certain speed. In contrast, the HFI approach can be operated effectively in a standstill and low-speed mode, and thus this approach is applicable to EVs requiring frequent starting with a highly developed torque. However, the current ripples caused by its inherent slotting effect must be considered when making the current control and the HFI rotor position estimation.

In the HFI sensorless mechanism with sinusoidal signal injection, low-pass filters (LPFs) are used for extracting the current signal containing the estimated position error. The inherent time delay of LPFs limits the dynamic performances of the current and speed loops. To overcome these difficulties, the square-wave HFI sensorless schemes have been proposed [28-33]. By increasing the injection frequency, the effect of slot harmonics can be reduced, and fixed-frequency injection can 
be adopted. The number of LPFs used in the estimation scheme is reduced, and thus the bandwidths of the current, speed, and position estimation schemes are improved. In recent studies [32, 33], the problem of instability under heavy loads has been pointed out, and to address it, improved squarewave HFI schemes have been proposed in order to enhance the performance of the motor under heavy load. However, only the ones at low speed are treated. At present, methods for achieving satisfactory driving characteristics under wide speed and load ranges for EV application are being pursued. As the speed and load are increased, the difference between $d$ - and q-axis inductances $\left(L_{d}-L_{q}\right)$ will be decreased to reduce the sensitivity of the rotor position estimation. The effects of the load- and speed-dependent slot harmonics and their multiples cannot be ignored, especially for a high-power motor drive with low switching frequency. The sinusoidal HFI schemes can be divided into the following: (i) Rotating voltage signal type- In this type, the balanced two-phase voltages are injected into the $d$ - as well as the q-axis. The sensed current along the two axes are processed through a band-pass filter, reverse rotating-frame transformation, low-pass filter, and the phaselocked loop (PLL) to yield the observed rotor angle. The inherent detected angle errors for the interior PMSM (IPMSM) and SynRM will exist while performing the rotating-frame transformation for the unbalanced $d$ - and q-axis currents due to the $L_{d} \neq L_{q}$ condition. (ii) Pulsating voltage signal type-In this type, only the d-axis (or q-axis) voltage is injected. The detected q-axis (or d-axis) current is used to yield the rotor angle via band-pass filtering, modulation, and servo regulation mechanism.

As far as the single-axis HFI scheme is concerned, for the surface PMSM (SPMSM), $L_{d}=L_{q}$. Thus, one can adopt the $d$ - or q-axis injection scheme to yield identical results. In the case of IPMSM, the rotor permanent magnet (PM) flux linkage $\lambda_{m}^{\prime r} \neq 0$ and $L_{d} \neq L_{q}$. Thus, choosing either the d-axis or the q-axis would depend on the saliency extent and the amplitude of back-EMF harmonics. Finally, for a SynRM, $\lambda_{m}^{\prime r}=0$ and $L_{d}>L_{q}$. Thus, considering the slot harmonic effect, the q-axis injection scheme is suggested to yield a stable and better performance under wider speed and load ranges. Analytic and experimental explorations presented in the latter part of the main text will show that the conventionally adopted $d$-axis injection scheme can not be stably operated above a certain load, even if changed injection frequencies are applied. In this paper, the theoretical and experimental explorations done for making an adequate choice of the injection mechanism have been presented. Further, the q-axis injection HFI sensorless EV SynRM drive has been described and evaluated experimentally.

\section{System Configuration}

\subsection{The Developed EV SynRM Drive}

The developed EV SynRM drive is shown in Figure 1. The direct current (DC)-link is powered from the battery via a bidirectional interface converter with boosted voltage to achieve better driving performance over a wide speed range. A dynamic brake leg has been incorporated to avoid the over-voltage caused by the failure of regenerative braking. 


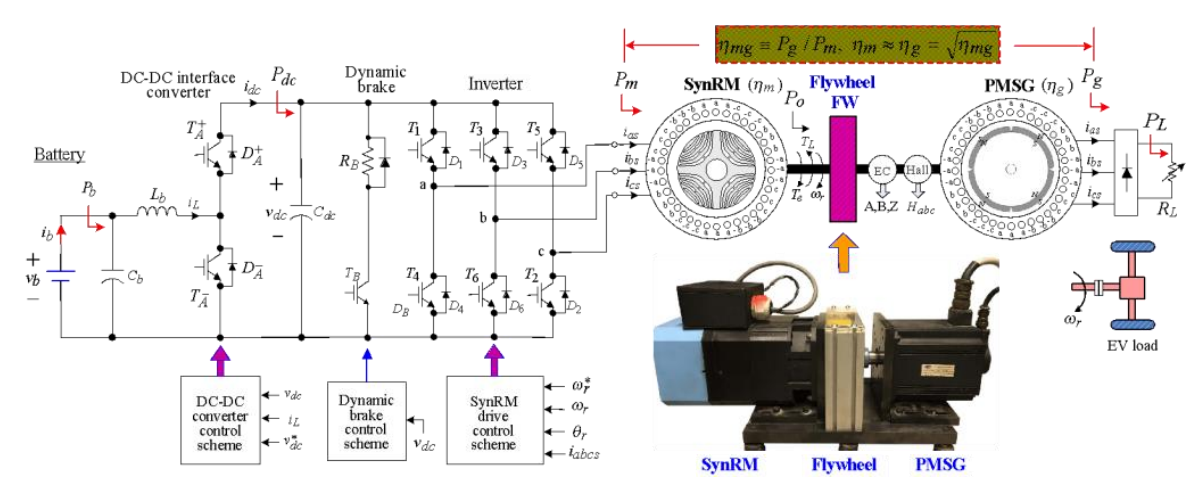

Figure 1 System configuration of the developed EV SynRM drive.

\subsubsection{Governing Equations of SynRM}

The voltage and developed torque of a SynRM in the $d$-q domain of the rotor frame can be expressed as $[1,2]$

$$
\begin{gathered}
{\left[\begin{array}{c}
v_{d s}^{r} \\
v_{q s}^{r}
\end{array}\right]=\left[\begin{array}{cc}
R_{s}+L_{d} \frac{d}{d t} & -\omega_{r} L_{q} \\
\omega_{r} L_{d} & L_{q} \frac{d}{d t}
\end{array}\right]\left[\begin{array}{c}
i_{d s}^{r} \\
i_{q s}^{r}
\end{array}\right]} \\
T_{e}=\frac{3 P}{4}\left[\left(L_{d}-L_{q}\right) i_{q s}^{r} i_{d s}^{r}\right]=\frac{3 P}{4}\left(\frac{L_{q}-L_{d}}{2}\right) \hat{I}_{a s}^{2} \sin 2 \beta=T_{L}+B \omega_{r}+J \frac{d \omega_{r}}{d t}
\end{gathered}
$$

where $\hat{I}_{a s}$ is the peak of the a-phase current and $\beta$ is the shift angle between the a-phase current peak and the $d$-axis. The $q$-and $d$-axis inductances are defined as

$$
L_{q}=L_{l s}+\frac{3}{2}\left(L_{A}-L_{B}\right), L_{d}=L_{l s}+\frac{3}{2}\left(L_{A}+L_{B}\right)
$$

\subsubsection{Observations}

(a) From Equation (2), it can be seen that the commutation angle for a SynRM drive must be set to $\beta=45^{\circ}$ theoretically. In reality, by considering the motor core losses and the saturated d-axis and $\mathrm{q}$-axis inductances, the actual shift angle $\beta>45^{\circ}$ must be properly tuned depending on the system operating conditions [5].

(b) Regenerative braking of a SynRM drive must be achieved by reversing the developed torque. For reversing the torque, two approaches are suggested. In the first approach, the q-axis current command is set to be negative when the motor speed starts decelerating and again set to be positive when the speed command reaches zero. In the second approach, the reversing of torque can be achieved by reversing the $\beta$-angle with respective to the $\mathrm{d}$-axis. In this study, the alternative approach of reversing the q-axis current, $i_{q s}^{r}$, has been adopted in the developed EV SynRM drive. The first approach has been implemented for regenerative braking, as described in the later section.

The EV SynRM drive system components are as follows:

(1) SynRM drive

- $\quad$ SynRM: 3P, 4-pole, $3.7 \mathrm{~kW}, 11.5 \mathrm{~A}, 2000 \mathrm{rpm}$.

- Load PMSG: 3P Y-connected, 8-pole, 5 kW, 2000 rpm. 
- Inverter: It was constructed using three insulated-gate bipolar transistor (IGBT) modules, CM100DY-12H. Sinusoidal pulse-width modulator (PWM) switching frequency $f_{s}=10 \mathrm{kHz}$.

(2) Battery interface converter

- Battery voltage: $V_{b}=160 \mathrm{~V}, 18 \mathrm{Ah},\left(\mathrm{LiFePO}_{4}\right)$

- DC-link voltage: $V_{d c}=550 \mathrm{~V}$.

- $\quad$ Power rating: $P_{d c}=3.75 \mathrm{~kW}, I_{b}=I_{L}=23.44 \mathrm{~A}$

- Switching frequency: $f_{S}=30 \mathrm{kHz}$.

(3) Dynamic brake: Braking resistance $R_{B}=30 \Omega / 100 \mathrm{~W}$ was used. The voltage command was set to $570 \mathrm{~V}$, and the bang-bang control was applied with a hysteresis band of $h=3 \mathrm{~V}$.

\subsection{Control Schemes}

The control schemes of the battery interface converter, the dynamic brake, and the EV SynRM drive are shown in Figures 2(a) to 2(c), respectively. Details of the design procedures and all the designed constituted controllers can be found in a previous study [5], which were simplified as follows:

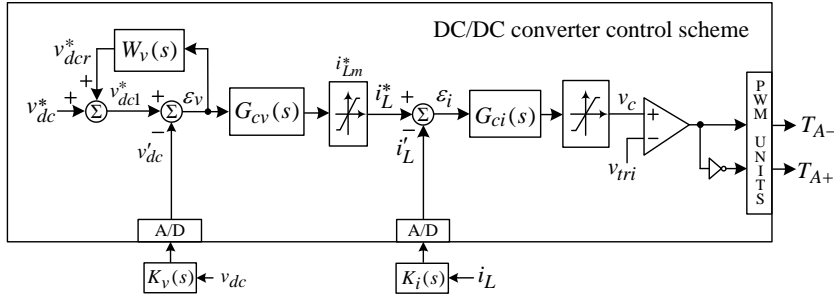

(a)

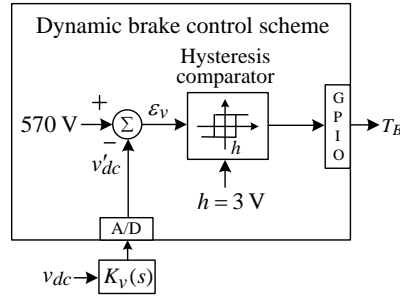

(b)

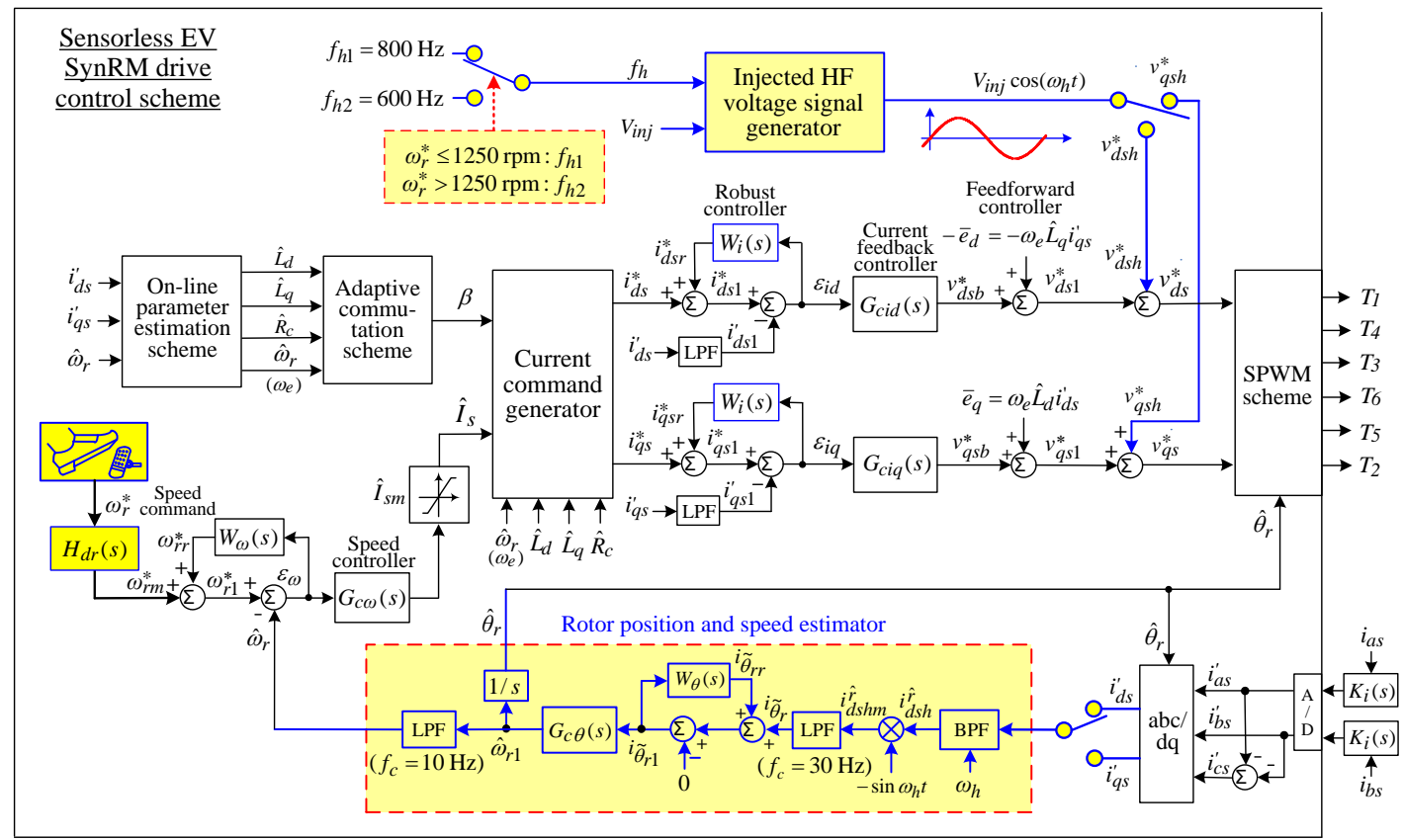

(c)

Figure 2 Control schemes of the developed sensorless EV SynRM drive. (a) battery interface converter, (b) dynamic brake, and (c) the motor drive. 


\subsubsection{Battery Interface Converter}

Current controller. Using a large-signal stability criterion for a ramp-comparison current control pulse-width modulator (RC-CCPWM), i.e., $\left(d v_{c} / d t\right)<\left(d v_{t r i} / d t\right)$, the upper limit of the proportional gain under the transient period after the occurrence of disturbance was obtained as $K_{p i}<11.54$. Choosing $K_{p i}=3$, the integral gain of $K_{I i}=10$ was then obtained by computeraided design with a cross-over frequency of $f_{c}=2.62 \mathrm{kHz}$. Finally,

$$
G_{c i}(s)=K_{p i}+\frac{K_{I i}}{s}=3+\frac{10}{s}
$$

Voltage controller. The controller $G_{c v}(s)$ was designed to have the desired voltage response due to a step load power change of $\Delta P_{d c}=201.67 \mathrm{~W}$. First, the voltage dynamic model was derived using arbitrarily set controller parameters, and then the designed controller was obtained by specifying the maximum voltage dip and rise time as follows:

$$
G_{c v}(s)=K_{p v}+\frac{K_{I v}}{s}=1.0558+\frac{15.6903}{s}
$$

$\underline{\text { Voltage robust controller. }}$

$$
W_{v}(s)=\frac{W_{v}}{1+\tau_{v} s}=\frac{0.5}{1+3.18 \times 10^{-3} s}
$$

Robustness analysis. From the derivation corresponding to the voltage loop shown in Figure 2(a), it can be observed that the voltage tracking error, $\varepsilon_{v}$, by the proportional-integral (PI) feedback controller, $G_{c v}(s)$, could only be reduced to $\left(1-W_{v}(s)\right) \varepsilon_{v} \approx\left(1-W_{v}\right) \varepsilon_{v}$. However, the control effort $i_{L}^{*}$ was magnified by a factor of $1 /\left(1-W_{v}\right)$. Thus, as the weighting factor, $W_{v}$, was chosen closer to 1.0, the feedback voltage would closely follow its command under different operating conditions. However, the magnified control effort and system noise would affect the system stability. Hence, a compromised consideration for determining the value of the robust control weighting factor $W_{v}$ must be made.

\subsubsection{SynRM Drive}

For the SynRM drive, the critical controllers include the following: (i) An adaptive commutation scheme (ACS), which was used for determining the commutation angle $\beta=\beta_{o}\left(\beta_{o}>45^{\circ}\right)$ using the fitted motor parameters $\left(\hat{L}_{d}, \hat{L}_{q}, \hat{R}_{c}\right)$ for minimizing the total copper and core losses in the motor. (ii) The d-axis and q-axis current control schemes, each consisting of a PI controller, a robust controller, and an observed back-EMF feedforward controller. The PI current controller was designed considering the inherent slot harmonic effects. (iii) Speed control scheme that was used for yielding quick speed tracking response under different operating conditions and a quantitatively designed PI feedback controller was augmented with a speed robust error cancellation controller (SRECC). The listed controller parameters are given as follows:

Current controller. Similar to the current control of a battery interface, the corresponding controller of the SynRM drive is expressed as: 


$$
G_{c i q}(s)=5+\frac{50}{s}, G_{c i d}(s)=10+\frac{100}{s}
$$

Speed controller. The dynamic model of the SynRM was estimated under a small step command change. By defining the speed command tracking response, the designed speed controller was derived as

$$
G_{c \omega}(s)=2.57334+\frac{1.1353576}{s}
$$

Robust controllers.

$$
\begin{gathered}
W_{i}(s)=\frac{W_{i}}{1+\tau_{i} s}=\frac{0.8}{1+3.18 \times 10^{-3} s} \\
W_{\omega}(s)=\frac{W_{\omega}}{1+\tau_{\omega} s}=\frac{0.4}{1+1.2538 \times 10^{-3} s}
\end{gathered}
$$

Similar to the robustness analysis made above, if the weighting factor, $W_{\omega}$, was chosen closer to 1.0; the motor speed would closely follow the speed command. Further, the speed regulation response due to load torque change could also be greatly improved. For a sensorless SynRM drive using the observed rotor speed, a low value of $W_{\omega}=0.4$ was chosen for reducing the effect of noise and the sluggish response of the observed speed.

The detailed analysis and design description of the proposed HFI sensorless control scheme will be presented in the following sections.

\section{Determination of the Key Attributes for the HFI Scheme}

For a pulsating HFI scheme [21-23], the high-frequency (HF) voltage can be injected into the qaxis (or d-axis), and the detected d-axis (or q-axis) current is processed to yield the observed rotor angle. In determining the adequate injected axis, the current levels in both axes must be observed. Hence, the back-EMF coupling effects were considered in the derivations.

For the injected high-frequency signal voltages, $v_{d s h}^{r}$ and $v_{q s h}^{r}$, at $\omega=\omega_{h}$, the voltage equations can be written from Equation (1) as

$$
\left[\begin{array}{l}
v_{d s h}^{r} \\
v_{q s h}^{r}
\end{array}\right]=\left[\begin{array}{cc}
z_{d h}^{r} & -\omega_{r} L_{q h}^{r} \\
\omega_{r} L_{d h}^{r} & z_{q h}^{r}
\end{array}\right]\left[\begin{array}{l}
i_{d s h}^{r} \\
i_{q s h}^{r}
\end{array}\right]
$$

where $z_{d h}^{r}=r_{d h}^{r}+j \omega_{h} L_{d h}^{r}$ and $z_{q h}^{r}=r_{q h}^{r}+j \omega_{h} L_{q h}^{r}$ are the impedances at $\omega_{h}$.

The relationship between the estimated rotor reference frame with the estimated rotor angle, $\hat{\theta}_{r}$, and the actual rotor reference frame is shown in Figure 3, where the rotor position estimation error is defined as

$$
\tilde{\theta}_{r} \triangleq \theta_{r}-\hat{\theta}_{r}
$$




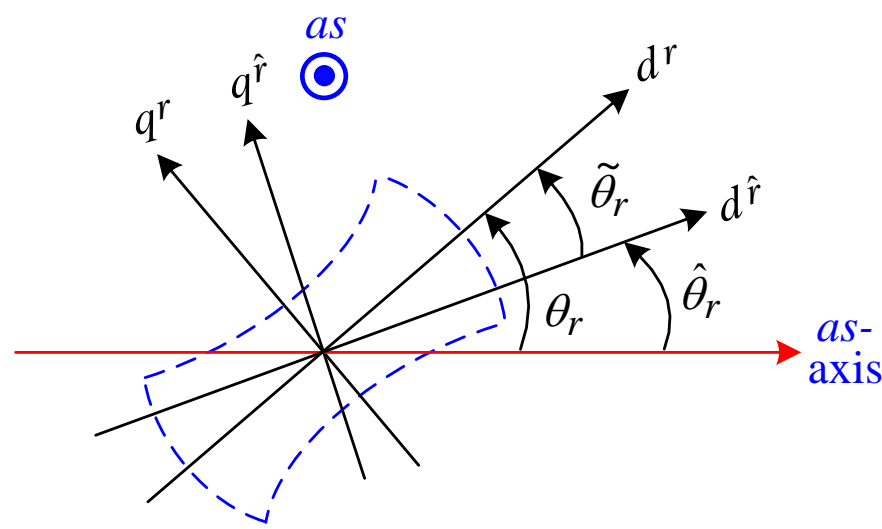

$\otimes$

$-a s$

Figure 3 Schematic showing the relationship between the estimated and the actual rotor reference frames.

Using $\widetilde{\theta}_{r}$, one can obtain the following high-frequency voltage equations:

$$
\left[\begin{array}{c}
v_{d s h}^{\hat{r}} \\
v_{q s h}^{\hat{r}}
\end{array}\right]=\left[\begin{array}{cc}
z_{d h}^{\hat{r}}-\omega_{r} L_{d i f f} \sin 2 \tilde{\theta}_{r} & z_{c h}^{\hat{r}}-\omega_{r} L_{a v g}+\omega_{r} L_{d i f f} \cos 2 \tilde{\theta}_{r} \\
z_{c h}^{\hat{r}}+\omega_{r} L_{a v g}+\omega_{r} L_{d i f f} \cos 2 \tilde{\theta}_{r} & z_{q h}^{\hat{r}}+\omega_{r} L_{d i f f} \sin 2 \tilde{\theta}_{r}
\end{array}\right]\left[\begin{array}{l}
i_{d s h}^{\hat{r}} \\
i_{q s h}^{\hat{r}}
\end{array}\right]
$$

where

$$
\begin{gathered}
z_{a v g} \triangleq \frac{z_{d h}^{r}+z_{q h}^{r}}{2}, z_{d i f f} \triangleq \frac{z_{d h}^{r}-z_{q h}^{r}}{2}, L_{a v g} \triangleq \frac{L_{d h}^{r}+L_{q h}^{r}}{2}, L_{d i f f} \triangleq \frac{L_{d h}^{r}-L_{q h}^{r}}{2} \\
z_{d h}^{\hat{r}}=z_{a v g}+z_{d i f f} \cos 2 \tilde{\theta}_{r}, z_{c h}^{\hat{r}}=z_{d i f f} \sin 2 \tilde{\theta}_{r}, z_{q h}^{\hat{r}}=z_{a v g}-z_{d i f f} \cos 2 \tilde{\theta}_{r}
\end{gathered}
$$

\subsection{D-axis Injection}

The normally employed d-axis injected mechanism is analyzed first. By applying the input voltage vector

$$
\left[\begin{array}{l}
v_{d s h}^{\hat{r}} \\
v_{q s h}^{\hat{r}}
\end{array}\right]=\left[\begin{array}{c}
V_{i n j} \cos \omega_{h} t \\
0
\end{array}\right]
$$

into Equation (13) and rearranging, the resultant q-axis current can be expressed as

$$
i_{q s h}^{\hat{r}}=\frac{z_{\text {diff }} \sin 2 \tilde{\theta}_{r}+\omega_{r} L_{a v g}+\omega_{r} L_{\text {diff }} \cos 2 \tilde{\theta}_{r}}{z_{\text {diff }}^{2}-z_{\text {avg }}^{2}+\omega_{r}^{2} L_{\text {diff }}^{2}-\omega_{r}^{2} L_{\text {avg }}^{2}} V_{\text {inj }} \cos \omega_{h} t
$$

\subsubsection{Observations}

The current expressed in Equation (17) contains the speed-dependent bias as well as the smallsignal terms with the information $\tilde{\theta}_{r}$. Although the former will be removed in the HFI modulation 
process, it exists in actual armature current, which affects the stable operation of an HFI sensorless SynRM drive.

Speed-dependent biased current. Generally, $\tilde{\theta}_{r}$ is very small under sensorless operation. By neglecting the terms included with $\tilde{\theta}_{r}$ in Equation (17), the component for estimating the current magnitude can be obtained as follows:

$$
\underline{i}_{q s h}^{\hat{r}}=\left(\frac{\left(-\omega_{r} L_{a v g}-\omega_{r} L_{\text {diff }}\right) V_{\text {inj }}}{z_{\text {avg }}^{2}-z_{\text {diff }}^{2}+\omega_{r}^{2} L_{\text {avg }}^{2}-\omega_{r}^{2} L_{\text {diff }}^{2}}\right) \cos \omega_{h} t=\left(\frac{\omega_{r} L_{d h}^{r} V_{\text {inj }}}{\omega_{h}^{2} L_{d h}^{r} L_{q h}^{r}-\omega_{r}^{2} L_{d h}^{r} L_{q h}^{r}}\right) \cos \omega_{h} t
$$

Small-signal current $\left(\widetilde{\theta}_{r}\right)$. By neglecting the $\omega_{r}$ terms and rearranging Equation (17), the current with $\tilde{\theta}_{r}$ is given by

$$
\tilde{l}_{q s h}^{\hat{r}}=\frac{z_{c h}^{\hat{r}} V_{i n j}}{z_{c h}^{\hat{r}^{2}}-z_{d h}^{\hat{r}} z_{q h}^{\hat{r}}} \cos \omega_{h} t=\frac{z_{d i f f} \sin 2 \tilde{\theta}_{r} V_{i n j}}{2 z_{d h} z_{q h}} \cos \omega_{h} t
$$

\subsection{Q-axis Injection}

The following q-axis injected vector was adopted:

$$
\left[\begin{array}{l}
v_{d s h}^{\hat{r}} \\
v_{q s h}^{\hat{r}}
\end{array}\right]=\left[\begin{array}{c}
0 \\
V_{i n j} \cos \omega_{h} t
\end{array}\right]
$$

Similarly, substituting Equation (20) into Equation (13), we get,

$$
i_{d s h}^{\hat{r}}=\frac{z_{\text {diff }} \sin 2 \tilde{\theta}_{r}-\omega_{r} L_{\text {avg }}+\omega_{r} L_{\text {diff }} \cos 2 \tilde{\theta}_{r}}{z_{\text {diff }}^{2}-z_{\text {avg }}^{2}+\omega_{r}^{2} L_{\text {diff }}^{2}-\omega_{r}^{2} L_{\text {avg }}^{2}} V_{\text {inj }} \cos \omega_{h} t
$$

Following the same procedure as above, the following current components can be obtained from Equation (21):

(i) Speed-dependent biased current

$$
\underline{i}_{d s h}^{\hat{r}}=\left(\frac{\left(\omega_{r} L_{a v g}-\omega_{r} L_{d i f f}\right) V_{i n j}}{z_{a v g}^{2}-\omega_{r}^{2} L_{d i f f}^{2}-z_{d i f f}^{2}+\omega_{r}^{2} L_{a v g}^{2}}\right) \cos \omega_{h} t=\left(\frac{-\omega_{r} L_{q h}^{r} V_{i n j}}{\omega_{h}^{2} L_{d h}^{r} L_{q h}^{r}-\omega_{r}^{2} L_{d h}^{r} L_{q h}^{r}}\right) \cos \omega_{h} t
$$

(ii) Small-signal current $\left(\widetilde{\theta}_{r}\right)$

$$
\tilde{i}_{d s h}^{\hat{r}}=\frac{z_{c h}^{\hat{r}} V_{i n j}}{z_{c h}^{\hat{r}^{2}}-z_{d h}^{\hat{r}} z_{q h}^{\hat{r}}} \cos \omega_{h} t=\frac{z_{d i f f} \sin 2 \tilde{\theta}_{r} V_{i n j}}{2 z_{d h} z_{q h}} \cos \omega_{h} t
$$

\subsubsection{Comments}

(1) From Equations (18), (19), (22), and (23), it is observed the small-signal currents, $\hat{\imath}_{q s h}^{\hat{r}}$ and $\hat{l}_{d s h}^{\hat{r}}$, for the two injection approaches are identical. However, $\hat{l}_{q s h}$ of $d$-axis injection is much larger than $\hat{l}_{d s h}$ of q-axis injection since the q-axis inductance is much lower than the $\mathrm{d}$-axis inductance for 
its air-slot rotor structure shown in Figure 1. From Equations (18) and (22), the defined current ratio is found to be

$$
C R_{i} \triangleq \frac{\left|\underline{i}_{q s h}^{\hat{r}}\right|}{\left|\underline{i}_{d s h}^{\hat{r}}\right|}=\frac{L_{d h}^{r}}{L_{q h}^{r}>1}
$$

(2) Hence, the q-axis injection scheme is suitable for a SynRM drive over a wide speed and load range, especially for EV drives. The numerical analysis of the experimental results will be presented in the subsection below, following the discussion on the experimental verification. The developed q-axis injected HFI EV SynRM drive will be presented in Section 4.

\subsection{Experimental Verification}

Let the established SynRM drive shown in Figure 1 be operated under the standard mode at $\omega_{r}^{*}=$ $2000 \mathrm{rpm}, R_{L}=16.67 \Omega$, and $\beta=\beta_{01}=45^{\circ}$. The high-frequency signal is injected into the $\mathrm{d}$ - as well as the q-axis, respectively. In the HFI scheme shown in Figure 2(c), the amplitude and frequency of the injected voltage were set as $V_{i n j}=25 \mathrm{~V}$ and $f_{h}=600 \mathrm{~Hz}$, and the band-pass filter (BPF) was chosen from experience as:

$$
H_{B P F}(s)=\frac{5.685 \times 10^{5} s^{2}}{s^{4}+1508 s^{3}+2.899 \times 10^{7} s^{2}+2.143 \times 10^{10} s+2.02 \times 10^{14}}
$$

with the center frequency being $600 \mathrm{~Hz}$.

\subsubsection{D-axis Injection}

First, the HF voltage was injected into the d-axis. The measured steady-state $\omega_{r}^{\prime},\left(i_{a s}^{\prime}, i_{d s}^{\prime}, i_{q s}^{\prime}\right)$, and the spectrum of $i_{a s}^{\prime}$ are shown in Figures 4(a) and 4(b). The corresponding q-axis current, $i_{q s}^{\prime}$, was sensed to yield the band-pass filtered $i_{q s h}^{\hat{r}}$, plotted in Figure 5(a), and its spectrum is shown in Figure 5(b).
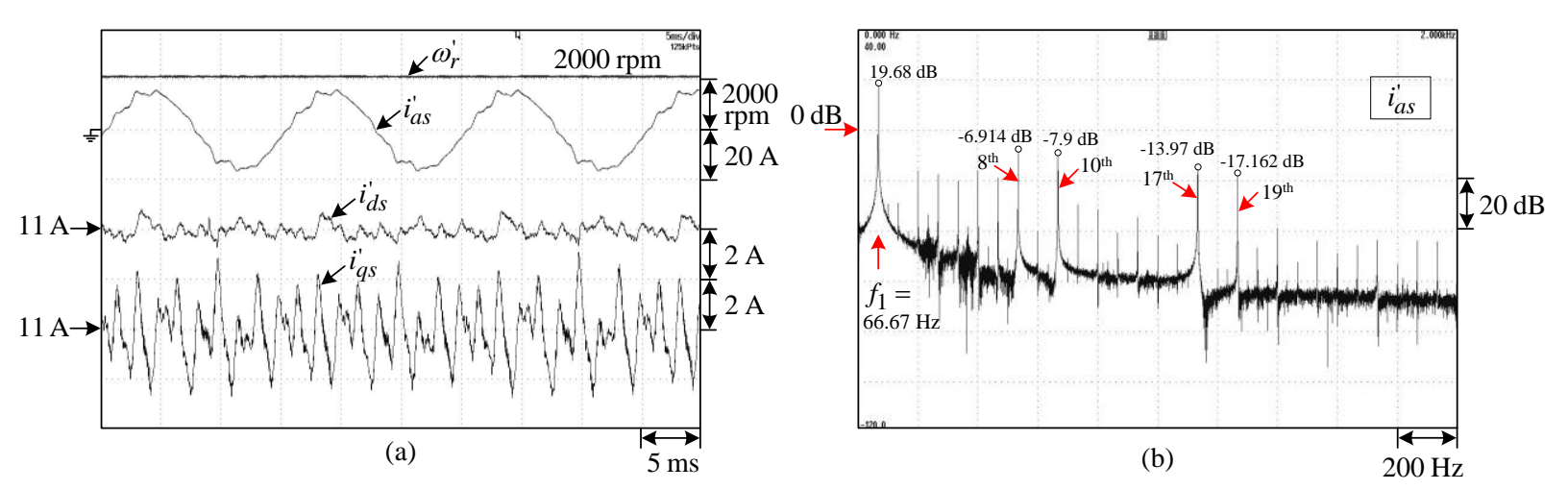

Figure 4 Measured steady-state characteristics of the developed standard EV SynRM drive at $\omega_{r}^{*}=2000 \mathrm{rpm}, R_{L}=16.67 \Omega$, and $\beta=\beta_{o 1}=45^{\circ}$ with the high-frequency voltage injected in the d-axis. (a) $\omega_{r}^{\prime}, i_{a s}^{\prime}, i_{d s}^{\prime}$, and $i_{q s}^{\prime}$, and (b) the spectrum of $i_{a s}^{\prime}$. 


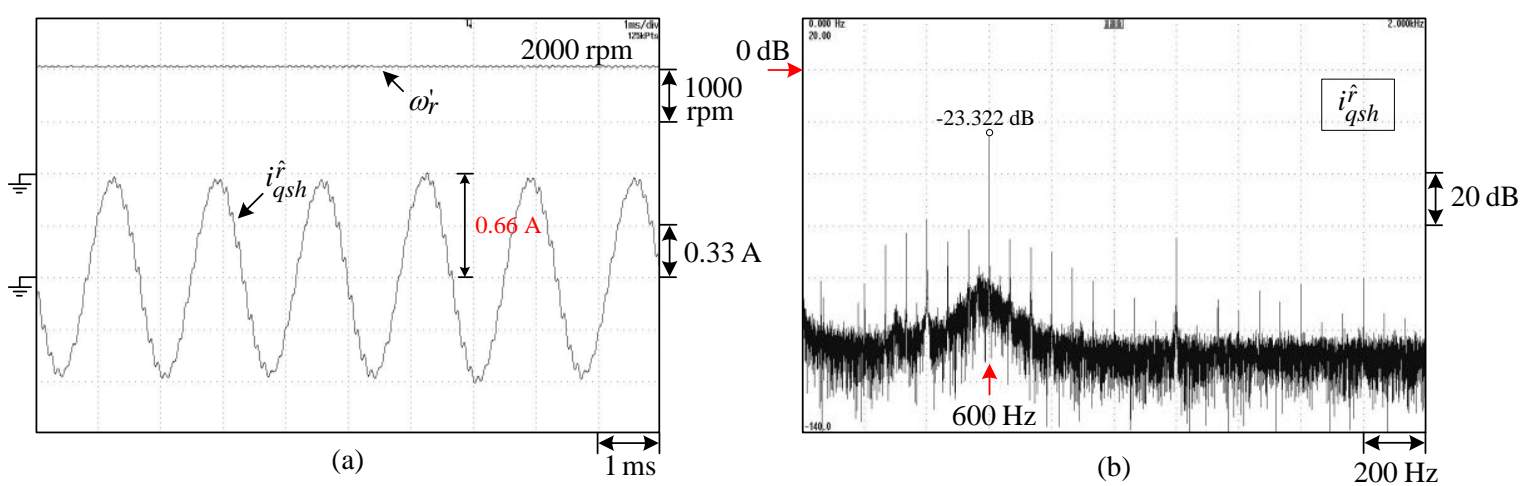

Figure 5 Measured steady-state characteristics of the developed standard EV SynRM drive at $\omega_{r}^{*}=2000 \mathrm{rpm}, R_{L}=16.67 \Omega$, and $\beta=\beta_{o 1}=45^{\circ}$ with the high-frequency voltage injected in the d-axis. (a) $\omega_{r}^{\prime}$ and $i_{q s h}^{\hat{r}}$, and (b) the spectrum of $i_{q s h}^{\hat{r}}$.

\subsubsection{Q-axis Injection}

Next, the injection was applied to the q-axis. The measured steady-state characteristics are plotted in Figure 6 and Figure 7.
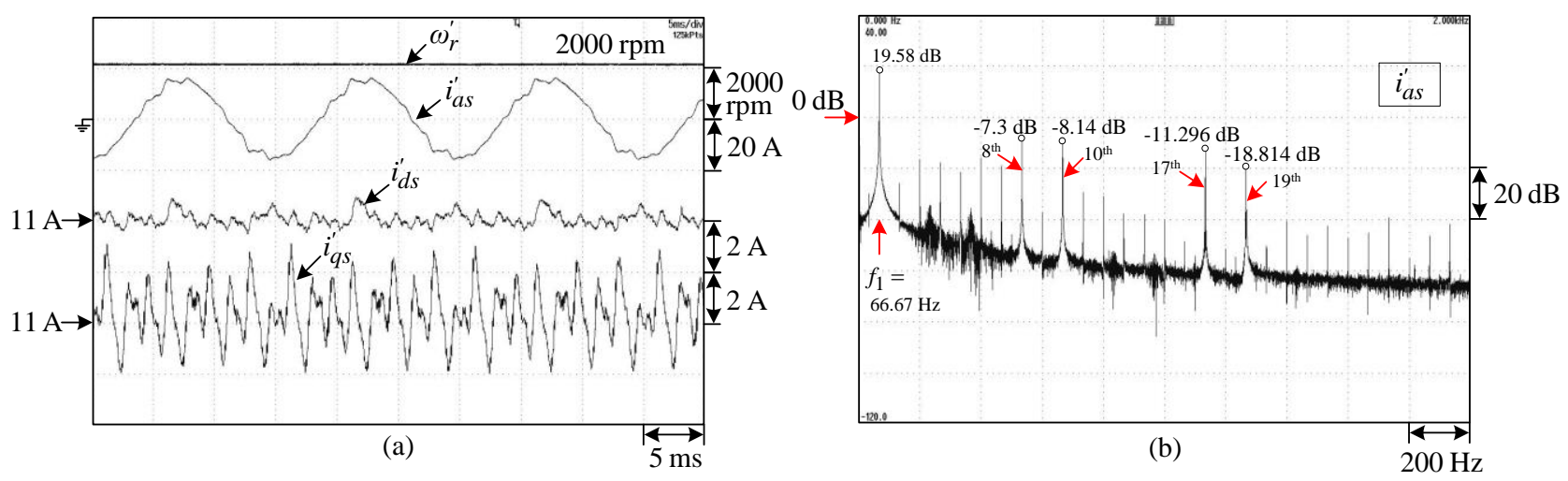

Figure 6 Measured steady-state characteristics of the developed standard EV SynRM drive at $\omega_{r}^{*}=2000 \mathrm{rpm}, R_{L}=16.67 \Omega$ and $\beta=\beta_{o 1}=45^{\circ}$ with the high-frequency voltage injected in the q-axis. (a) $\omega_{r}^{\prime}, i_{a s}^{\prime}, i_{d s}^{\prime}$, and $i_{q s}^{\prime}$, and (b) the spectrum of $i_{a s}^{\prime}$.
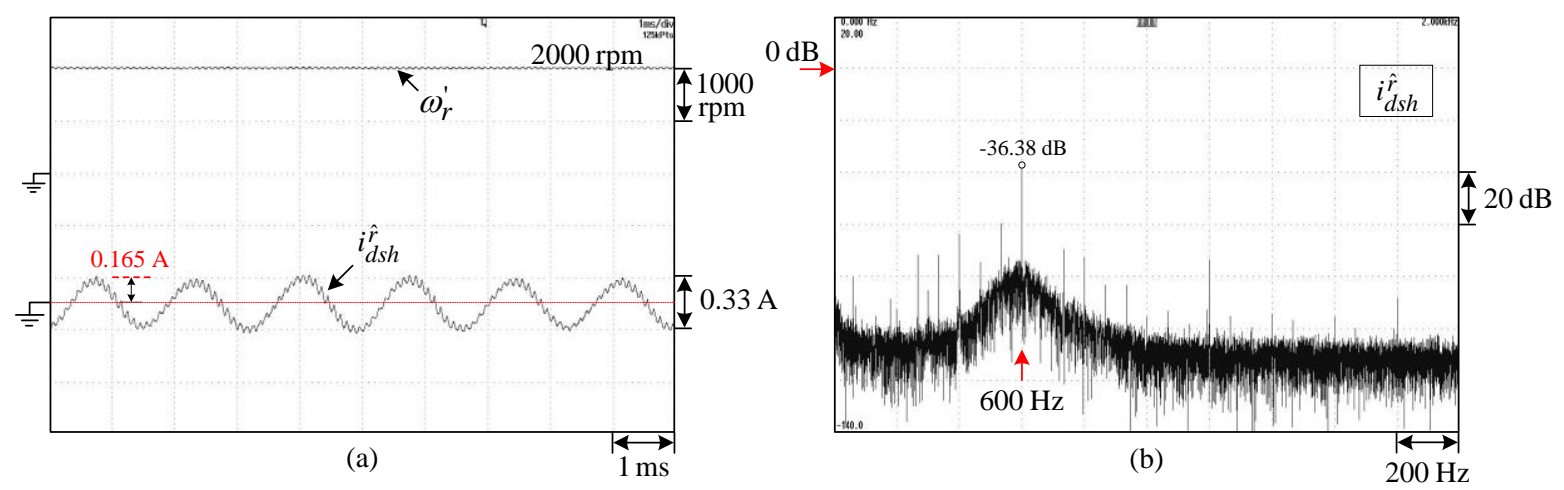

Figure 7 Measured steady-state characteristics of the deve loped standard EV SynRM drive at $\omega_{r}^{*}=2000 \mathrm{rpm}, R_{L}=16.67 \Omega$, and $\beta=\beta_{o 1}=45^{\circ}$ with the high-frequency voltage injected in the q-axis. (a) $\omega_{r}^{\prime}$ and $i_{d s h}^{\hat{r}}$, and (b) the spectrum of $i_{d s h}^{\hat{r}}$. 


\subsubsection{Comments}

(i) From the measured results shown in Figures 5 and 7, it can be seen that the ratio of the magnitude of the q-axis current $\left(i i_{q s h}^{\hat{r}}\right)$ to the magnitude of the d-axis current $\left(i \hat{r}_{d s h}\right)$ is $C R_{i}=$ $0.66 / 0.165=4.0$.

(ii) For theoretical proof, the motor is running at $\omega_{r}^{\prime}=2000 \mathrm{rpm}, R_{L}=16.67 \Omega$ and $\beta_{o}=45^{\circ}$ and an injected frequency of $f_{h}=600 \mathrm{~Hz}$. The steady-state current $i_{d s}=i_{q s}=\hat{I}_{s} \cos \beta=11 \mathrm{~A}$ is obtained from the results. The inductances at $11 \mathrm{~A}$ are $L_{d}=44.6 \mathrm{mH}$ and $L_{q}=11.3 \mathrm{mH}$ from the fitted curves in [5]. The magnitude of the q-and d-axis currents from Equations (18) and (22) are found to be

$$
\begin{aligned}
& \underline{i}_{q s h}^{\hat{r}}=\left(13.08 \times 10^{-4}\right) V_{i n j} \cos \omega_{h} t \\
& \underline{i}_{d s h}^{\hat{r}}=\left(3.314 \times 10^{-4}\right) V_{i n j} \cos \omega_{h} t
\end{aligned}
$$

Hence, analytically, from Equations (24) and (25), $C R_{i}=13.08 / 3.3314=44.6 / 11.3=$ 3.947. The signal ratio is also $\left(S R_{i q}\right) /\left(S R_{i d}\right)=C R_{i}=3.947$. Hence, the measured results are close to the analytic values, and the explored facts are thus confirmed.

\subsection{Slotting Effect of the HFI Operation}

\subsubsection{Current Harmonics by Slotting Effect}

The inverter-powered stationary armature winding facing the rotating slotted rotor can yield ripple currents. The dominant low-order current harmonics of the employed SynRM are $h=17$ and 19. Accordingly, the transformed d-axis and q-axis currents possess the ripples $(h=(17+19) / 2=18)$ to affect the current control and the HFI operation. Hence, the key HFI parameters must be set appropriately, as will be described in Section 4.2.

\subsubsection{Spectral Characteristics}

During real operation, the injected frequency is fixed, whereas the $d-q$ domain slot harmonic frequency $f_{s l}=18 f_{1}$ is varied with the fundamental frequency, and its magnitude is increased with the load. As the slot harmonic frequency gradually approaches the injected frequency, the estimated rotor angle will exhibit oscillations, leading to unstable operation. Hence, the changed injection frequencies must be adopted to avoid the oscillating behavior of the rotor as $f_{s l}$ is close to the injected frequency $f_{h}$.

\subsection{Injected Axis Choice for Pulsating Voltage Injection}

From the previous exploration, the following distinct facts for an HFI SynRM drive can be noted: (i) The $\mathrm{d}$-q slot harmonic currents increase with the load at the frequency $f_{s l}=18 f_{1}$. (ii) The resultant currents increase with the speed, $\omega_{r}$, with $C R_{i}=L_{d h}^{r} / L_{q h}^{r}>1$ and the current of d-axis injection is much larger. Hence, (iii) as the load and/or speed are increased, the d-axis injection scheme is prone to become unstable. Thus, for yielding a stable operation of the sensorless EV SynRM drive over a wide speed and load range, q-axis injection has been adopted in this work. 


\section{The Developed HFI Position Sensorless EV SynRM Drive}

\subsection{System Configuration and Operation Principle}

The control scheme of the developed q-axis injected HFI sensorless SynRM drive is shown in Figure 2(c), and the proposed changed-frequency injection mechanism and the frequency distributions are shown in Figures 8(a) and 8(b). The HF voltage, $v_{q s h}^{*}=V_{i n j} t(V)$, with changed frequencies is injected into the q-axis, and the d-axis current is detected to yield the estimated rotor position and speed via proper signal processing. The small-signal current with $\tilde{\theta}_{r}$ can be directly obtained from Equation (21) by neglecting the $\omega_{r}$ terms.
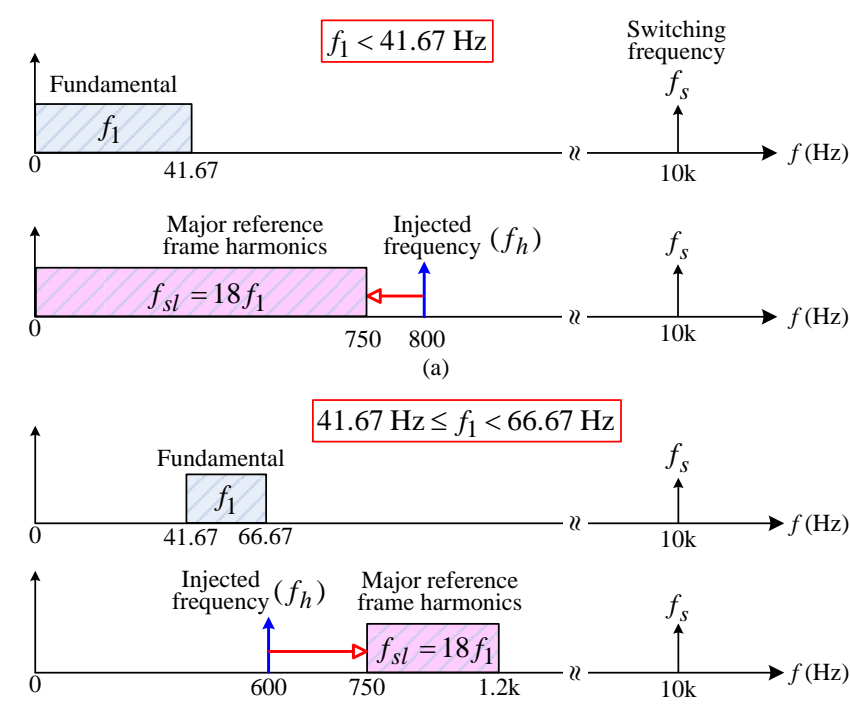

(b)

Figure 8 Frequency distribution in the proposed changed frequencies injection mechanism for (a) $f_{1}<41.67 \mathrm{~Hz}$ and (b) $41.67 \mathrm{~Hz} \leq f_{1}<66.67 \mathrm{~Hz}$.

The small-signal current, as a function of $\tilde{\theta}_{r}$, of the proposed q-axis injected HFI sensorless SynRM can be re-expressed from Equation (22) as follows [23]:

$$
\hat{\imath}_{d s h}^{\hat{r}_{h}}=\left(\frac{z_{d i f f} \sin 2 \tilde{\theta}_{r}}{2 z_{d h} z_{q h}} V_{i n j}\right) \cos \omega_{h} t
$$

Generally, $\tilde{\theta}_{r}$ is very small under sensorless operation and $\omega_{h} L_{\text {diff }}>>r_{\text {diff }}$. Thus, Equation (26) can be simplified to

$$
i_{d s h}^{\hat{r}}=\frac{V_{\text {inj }}}{2}\left[\frac{-\omega_{h} L_{d i f f} \sin \omega_{h} t}{\omega_{h}^{2} L_{d h}^{r} L_{q h}^{r}}\right] \sin 2 \tilde{\theta}_{r}
$$

Based on Equation (27), the rotor position and speed estimation scheme are shown in Figure 9(a). In order to yield the rotor position estimation error from Equation (27), a BPF was adopted to extract the high-frequency current, $i_{d s h}^{\hat{r}}$, from the sensed current, $i_{d s}^{\prime}$. Then, $i_{d s h}^{\hat{r}}$ was multiplied by $(-t)$ to yield 


$$
i_{d s h}^{\hat{r}} \times\left(-\sin \omega_{h} t\right)=\frac{V_{\text {inj }}}{2}\left[\frac{\omega_{h} L_{d i f f} \sin 2 \tilde{\theta}_{r}}{\omega_{h}^{2} L_{d h}^{r} L_{q h}^{r}}\right]\left[\frac{1-2 \cos \omega_{h} t}{2}\right]
$$

The signal in Equation (28) is composed of a DC and a 2nd order harmonic component. Using an LPF, the DC component, $i_{\widetilde{\theta}_{r}}$, can be extracted as follows:

$$
i_{\widetilde{\theta}_{r}}=\operatorname{LPF}\left[i_{q s h}^{\hat{r}} \times\left(-\sin \omega_{h} t\right)\right] \cong \frac{V_{\text {inj }} L_{d i f f}}{4 \omega_{h}^{2} L_{d h}^{r} L_{q h}^{r}} \sin 2 \tilde{\theta}_{r}
$$

Further, applying linearization to Equation (29), we get,

$$
i_{\widetilde{\theta}_{r}} \approx \frac{V_{i n j} L_{d i f f}}{2 \omega_{h} L_{d h}^{r} L_{q h}^{r}} \tilde{\theta}_{r} \triangleq K_{e r r} \tilde{\theta}_{r}, K_{e r r} \triangleq \frac{V_{i n j} L_{d i f f}}{2 \omega_{h} L_{d h}^{r} L_{q h}^{r}}
$$

Equation (30) indicates that $i_{\widetilde{\theta}_{r}}$ is proportional to the rotor position error, $\tilde{\theta}_{r}$, by a sensitivity factor, $K_{\text {err }}$. In the rotor position and speed estimation scheme shown in Figure 9(a), the disturbance signal is eliminated by a PI controller,

$$
G_{c \theta}(s)=K_{P \widehat{\omega}}+\frac{K_{I \widehat{\omega}}}{s}
$$

to yield the estimated rotor speed. Then, the estimated rotor position is obtained by the integration process.

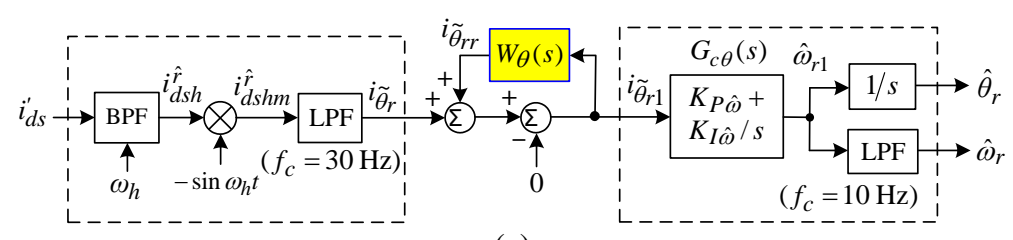

(a)

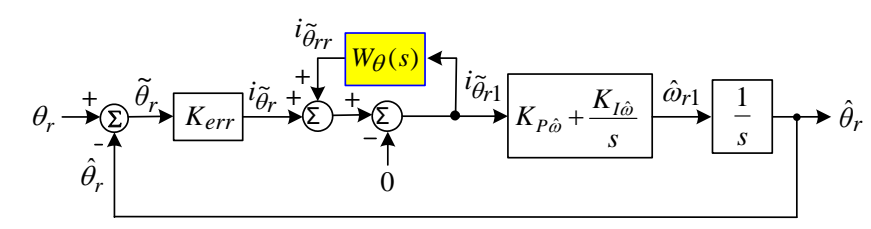

(b)

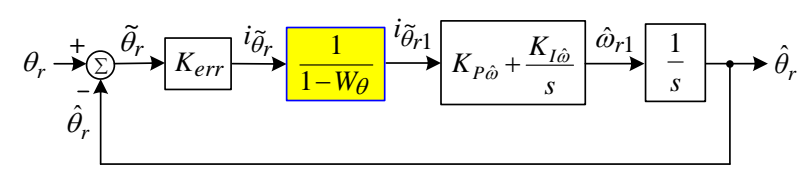

(c)

Figure 9 Rotor position and speed estimation scheme based on the q-axis injection scheme. (a) the estimation mechanism, (b) equivalent estimated rotor position tracking control block, and (c) equivalent block of (b) after adding PRECC.

To enhance the rotor position estimation performance, an estimated position robust error cancellation controller (PRECC) with the following weighting function was added: 


$$
W_{\theta}(s)=\frac{W_{\theta}}{1+\tau_{\theta} s} \approx W_{\theta}, 0 \leq W_{\theta}<1.0
$$

Similarly, the LPF time-constant, $\tau_{\theta}$, and the weighting factor, $W_{\theta}$, must be properly chosen to yield the compromised performance, considering the effects of system noise and the sluggish response of the observed rotor position.

The equivalent tracking control block representing the HFI sensorless control scheme can be presented by the block diagram shown in Figure 9(b), and its equivalent block obtained through derivation after applying the robust control is presented in Figure 9(c). The closed-loop tracking transfer function is found to be

$$
H_{d \theta}(s)=\frac{\hat{\theta}_{r}}{\theta_{r}}=\frac{K_{P \widehat{\omega}} K^{\prime}{ }_{e r r} s+K_{I \widehat{\omega}} K^{\prime}{ }_{\text {err }}}{s^{2}+K_{P \widehat{\omega}} K^{\prime}{ }_{e r r} s+K_{I \widehat{\omega}} K^{\prime}{ }_{\text {err }}}
$$

with

$$
K^{\prime}{ }_{\text {rrr }} \equiv \frac{1}{1-W_{\theta}} K_{e r r}
$$

From Equations (33) and (34), the following facts can be noted: (i) Since $H_{d \theta}(0)=1$, there is no steady-state rotor position estimation error. (ii) By adding the robust control, the sensitivity factor $K_{\text {err }}$ becomes $K_{\text {err }}^{\prime} \equiv K_{\text {err }} /\left(1-W_{\theta}\right)$, or equivalently, the estimated position error can be reduced by a factor of $\left(1-W_{\theta}\right)$. However, the effect of the system noise and the estimated response delay must be considered.

\subsection{HFI Scheme System Parameters}

(1) Injected voltage: $v_{q s h}=V_{i n j} \sin \omega_{h} t(\mathrm{~V}), V_{i n j}=60 \mathrm{~V}$, and

$$
\begin{gathered}
0 \leq \omega_{r} \leq 1250 \mathrm{rpm} \Rightarrow f_{h}=f_{h 1}=800 \mathrm{~Hz} . \\
1250 \mathrm{rpm}<\omega_{r} \leq 2000 \mathrm{rpm} \Rightarrow f_{h}=f_{h 2}=600 \mathrm{~Hz} .
\end{gathered}
$$

(2) Rotor position estimation regulator: $G_{c \theta}(s)=4+\frac{60}{s}$

Robust rotor position error cancellation controller:

$$
W_{\theta}(s)=\frac{W_{\theta}}{1+\tau_{\theta} s}=\frac{0.3}{1+0.00318 s}
$$

(3) Signal processing filters:

$$
\begin{gathered}
\text { LPF of } i_{d s}^{\prime} \text { and } i_{q s}^{\prime}: H_{L F}(s)=1 /(1+0.00159 s) . \\
\operatorname{LPF} \text { of } i_{\widetilde{\theta}_{r}}: H_{L F}(s)=1 /(1+0.0053 s) . \\
\operatorname{LPF} \text { of } \widehat{\omega}_{r}: H_{L F}(s)=1 /(1+0.0159 s) .
\end{gathered}
$$


BPFs of $i_{d s h}^{\hat{r}_{n}}$ : The used ones under $f_{h}=800 \mathrm{~Hz}$ and $600 \mathrm{~Hz}$ were:

$$
\begin{aligned}
& H_{B P F}(800 \mathrm{~Hz})=\frac{1.011 \times 10^{6} s^{2}}{s^{4}+2011 s^{3}+5.145 \times 10^{7} s^{2}+5.08 \times 10^{10} s+6.384 \times 10^{14}} \\
& H_{B P F}(600 \mathrm{~Hz})=\frac{5.685 \times 10^{5} s^{2}}{s^{4}+1508 s^{3}+2.899 \times 10^{7} s^{2}+2.143 \times 10^{10} s+2.02 \times 10^{14}}
\end{aligned}
$$

\subsection{Comparative Evaluation of the $d$-axis and q-axis Injected SynRM Drives}

\subsection{1 d-axis Injection Scheme}

As explored above, for d-axis injection, the resultant current level of $i_{q s h}^{\hat{r}}$ is much larger than that of q-axis injection. Hence, for stable operation, the key parameters of the HFI scheme were carefully set to the following values:

(1) Injected voltage: $v_{d s h}=V_{i n j} \sin \omega_{h} t(\mathrm{~V}), V_{i n j}=40 \mathrm{~V}$ and

$$
\begin{gathered}
850 \mathrm{rpm} \leq \omega_{r} \leq 1250 \mathrm{rpm} \Rightarrow f_{h}=f_{h 1}=450 \mathrm{~Hz} . \\
\omega_{r}<850 \mathrm{rpm}, \omega_{r}>1250 \mathrm{rpm} \Rightarrow f_{h}=f_{h 2}=600 \mathrm{~Hz} .
\end{gathered}
$$

(2) Rotor position estimation regulator: $G_{c \theta}(s)=4+\frac{40}{s}$

(3) BPFs of $i_{q s h}^{\hat{r}}$ : The BPFs adopted under $f_{h}=450 \mathrm{~Hz}$ and $600 \mathrm{~Hz}$ were:

$$
\begin{aligned}
& H_{B P F}(450 \mathrm{~Hz})=\frac{566}{s^{2}+566 s+7.99 \times 10^{6}} \\
& H_{B P F}(600 \mathrm{~Hz})=\frac{754}{s^{2}+754 s+1.42 \times 10^{7}}
\end{aligned}
$$

\subsubsection{Comparative Evaluation}

At $V_{d c}=550 \mathrm{~V}$, and $R_{L}=33.33 \Omega$, Figures $10(\mathrm{a})$ to 10 (c) show the measured values of $\omega_{r}^{*}$ and $\widehat{\omega}_{r}$ as a function of time and the estimated rotor position error $\theta_{e r r}\left(\triangleq-\tilde{\theta}_{r}=\hat{\theta}_{r}-\theta_{r}\right)$ of the developed q-axis injected HFI sensorless SynRM drive resulting from the preset speed pattern of $\omega_{r}^{*}=0 \rightarrow 2000 \rightarrow 0 \mathrm{rpm}$ and acceleration/deceleration rates of $100 \mathrm{rpm} / \mathrm{s}$ with $\left(W_{\theta}=\right.$ $\left.0, W_{\omega}=0\right),\left(W_{\theta}=0.3, W_{\omega}=0.0\right)$, and $\left(W_{\theta}=0.3, W_{\omega}=0.4\right)$. From the figures, the gradual decrease in $\theta_{e r r}$ and $\varepsilon_{\omega}\left(\omega_{r}^{*}-\widehat{\omega}_{r}\right)$ after adding $W_{\theta}$ and $W_{\omega}$ can be observed. 


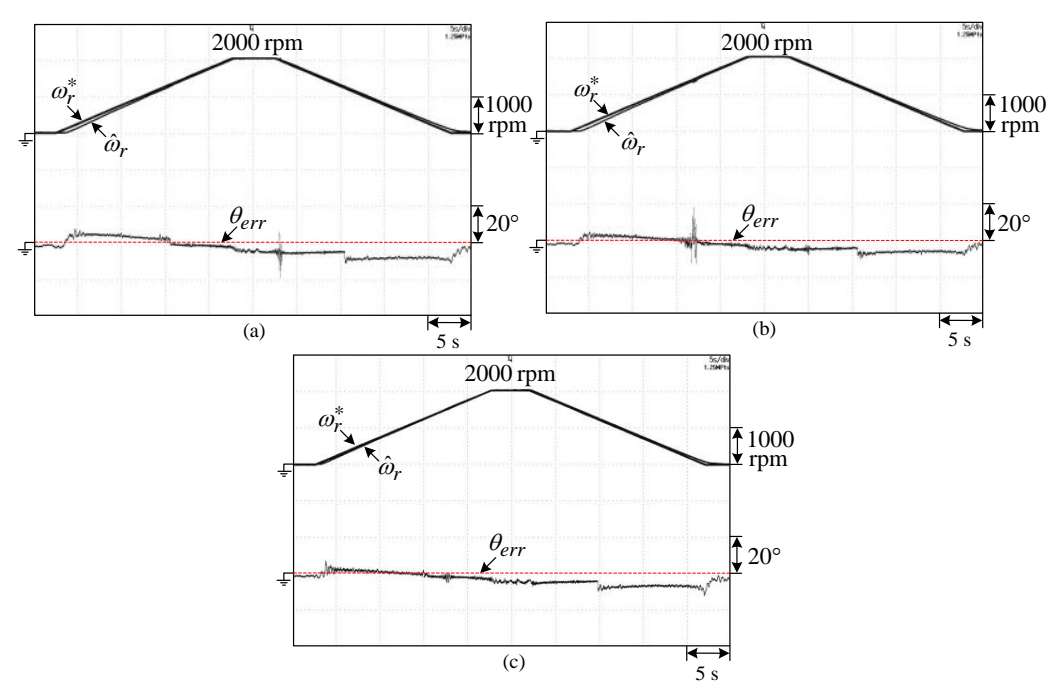

Figure 10 Measured time variation of $\omega_{r}^{*}, \widehat{\omega}_{r}$, and $\theta_{\text {err }}$ of the established q-axis injected $\mathrm{HFI}$ sensorless EV SynRM drive as the speed command changes in the order $\omega_{r}^{*}=0 \rightarrow$ $2000 \rightarrow 0 \mathrm{rpm}$, with the acceleration/deceleration rates being $100 \mathrm{rpm} / \mathrm{s}$ at $V_{d c}=$ $550 \mathrm{~V}, R_{L}=33.33 \Omega$, and $\beta=\beta_{o}$. (a) results for $W_{\theta}=0, W_{\omega}=0$, (b) results for $W_{\theta}=0.3, W_{\omega}=0$, and (c) results for $W_{\theta}=0.3, W_{\omega}=0.4$.

Figures 11(a) and 11(b) show the measured values of $\omega_{r}^{*}, \widehat{\omega}_{r}$ and $\theta_{\text {err }}$ of the d-axis and q-axis injected SynRM drives at $V_{d c}=550 \mathrm{~V}$ and $R_{L}=33.33 \Omega$. All normal operations can be seen, and the case of q-axis injected SynRM drives yields smaller $\theta_{\text {err }}$.
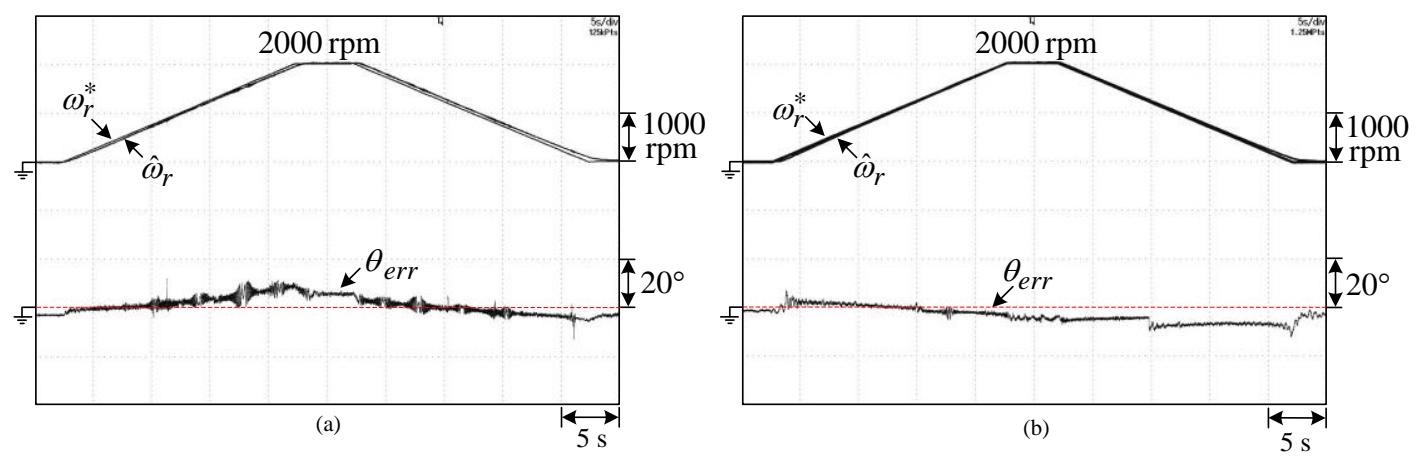

Figure 11 Measured time variation of $\omega_{r}^{*}, \widehat{\omega}_{r}$, and $\theta_{\text {err }}$ of the established HFI sensorless EV SynRM drive as the speed command changes in the order $\omega_{r}^{*}=0 \rightarrow 2000 \rightarrow 0 \mathrm{rpm}$, with the acceleration/deceleration rates being $100 \mathrm{rpm} / \mathrm{s}$ at $V_{d c}=550 \mathrm{~V}, R_{L}=$ $33.33 \Omega$, and $\beta=\beta_{o}$. (a) results for $\mathrm{d}$-axis injection, and (b) results for $\mathrm{q}$-axis injection.

The results of d-axis injection when the load is further increased to $R_{L}=32 \Omega$ is shown in Figure 12(a). From the figure, it can be seen that $\theta_{\text {err }}$ becomes worse compared to that observed from Figure 11(a). Figures $11(\mathrm{a})$ and $12(\mathrm{a})$ also indicate that $\theta_{\text {err }}$ increases with speed and load, as explored theoretically. As the load is slightly increased to $R_{L}=31.247 \Omega$, the d-axis injected SynRM drive fails to operate, as can be observed from Figure 12(b). Hence, q-axis injection was adopted for further measured results. 

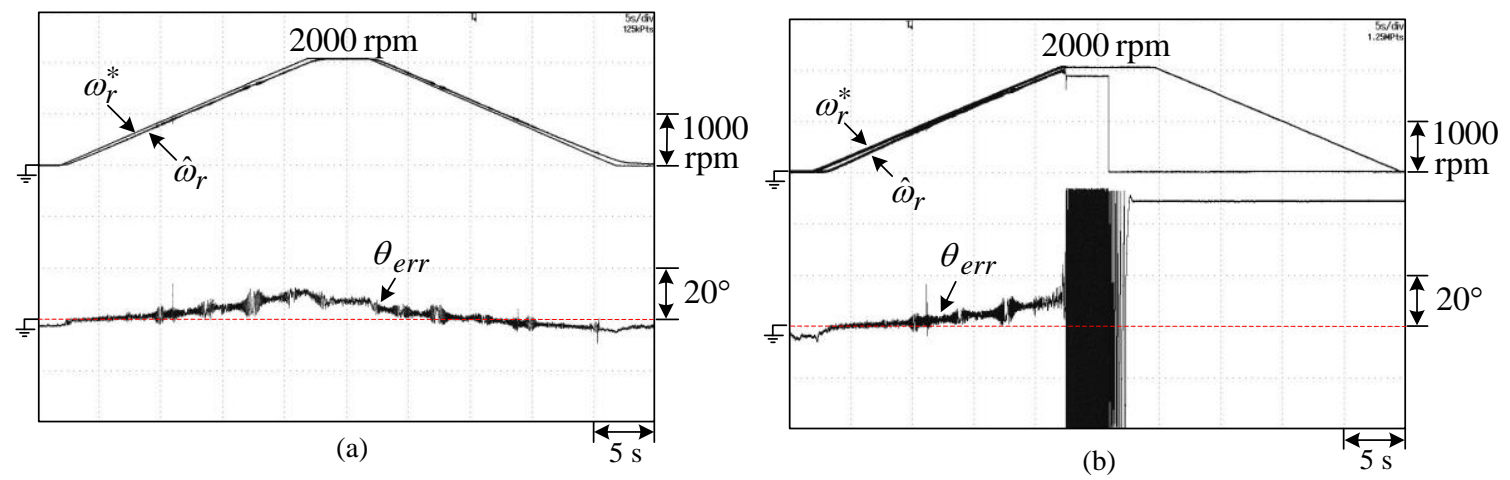

Figure 12 Measured time variation of $\omega_{r}^{*}, \widehat{\omega}_{r}$, and $\theta_{\text {err }}$ of the established $\mathrm{d}$-axis injected $\mathrm{HFI}$ sensorless EV SynRM drive as the speed command changes in the order $\omega_{r}^{*}=0 \rightarrow$ $2000 \rightarrow 0 \mathrm{rpm}$, with the acceleration/deceleration rates being $100 \mathrm{rpm} / \mathrm{s}$ at $V_{d c}=$ $550 \mathrm{~V}$ and $\beta=\beta_{o}$. (a) results for $R_{L}=32 \Omega$, and (b) results for $R_{L}=31.247 \Omega$.

Figures 13(a) and 13(b) show the measured time variation of $\omega_{r}^{*}, \widehat{\omega}_{r}$, and $\theta_{\text {err }}$ of the developed q-axis injected SynRM drive with $W_{\theta}=0.3, W_{\omega}=0.4$, and $V_{d c}=550 \mathrm{~V}$ for two different loads, respectively. Smoother operation and satisfactory driving performance can be observed from the results.
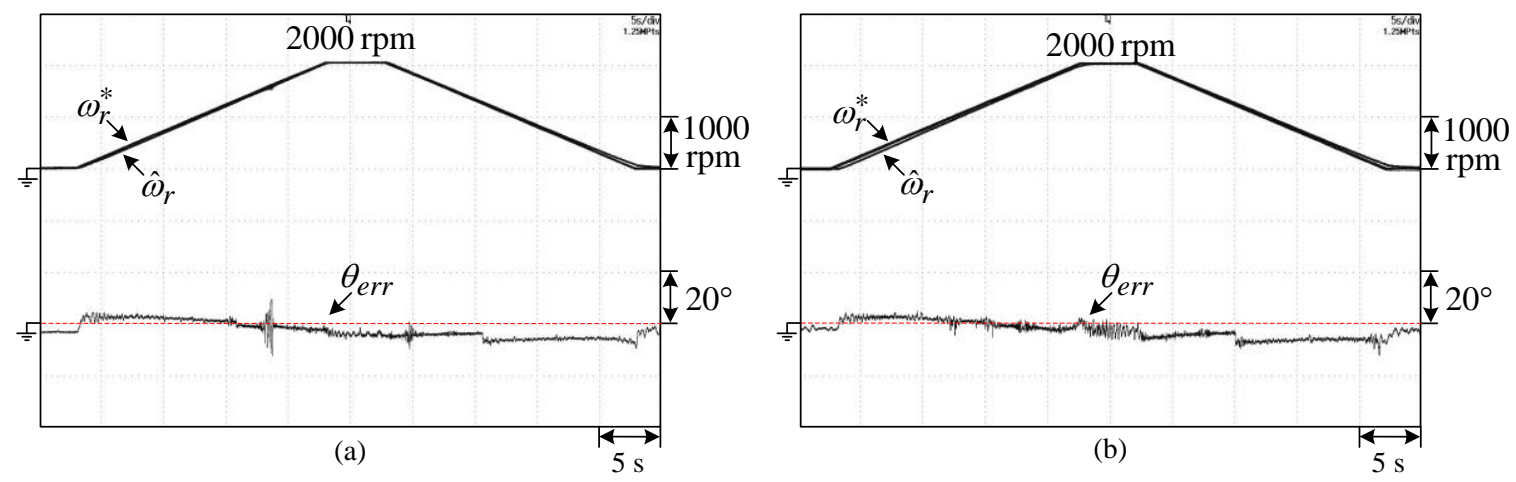

Figure 13 Measured time variation of $\omega_{r}^{*}, \widehat{\omega}_{r}$, and $\theta_{\text {err }}$ of the established q-axis injected $\mathrm{HFI}$ sensorless EV SynRM drive as the speed command changes in the order $\omega_{r}^{*}=0 \rightarrow$ $2000 \rightarrow 0 \mathrm{rpm}$, with the acceleration/deceleration rates of $100 \mathrm{rpm} / \mathrm{s}$ at $V_{d c}=$ $550 \mathrm{~V}$ and $\beta=\beta_{o}$. (a) results for $R_{L}=25 \Omega$ and (b) results for $R_{L}=16.67 \Omega$.

\subsection{Operation Characteristics of the Developed q-axis Injected EV SynRM Drive}

\subsubsection{Starting Process}

Figure 14 shows the measured time variation of $\theta_{r}, \hat{\theta}_{r}$, and $\theta_{\text {err }}$ of the developed $q$-axis injected HFI position sensorless EV SynRM drive during the starting process with the speed rising rate of 100 $\mathrm{rpm} / \mathrm{s}, V_{d c}=550 \mathrm{~V}, R_{L}=16.67 \Omega$, and $\beta=\beta_{o}$. The results show the smooth starting process. 


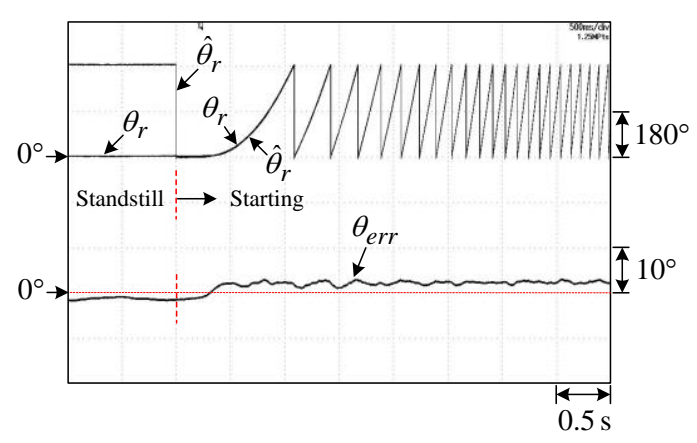

Figure 14 Measured time variation of $\theta_{r}, \hat{\theta}_{r}$, and $\theta_{\text {err }}$ during starting process of the developed sensorless SynRM drive with the speed rising rate of $100 \mathrm{rpm} / \mathrm{s}, V_{d c}=$ $550 \mathrm{~V}, R_{L}=16.67 \Omega$, and $\beta=\beta_{o}$.

\subsubsection{Steady- state Characteristics}

The measured time variation of $\left(\theta_{r}, \hat{\theta}_{r}, \theta_{e r r}\right),\left(\omega_{r}^{*}, \widehat{\omega}_{r}\right)$, and $\left(i_{a s}^{*}, i_{a s}^{\prime}\right)$ of the developed drive is presented in Figures $15(\mathrm{a})$ and $15(\mathrm{~b})$ for the speed command of $\omega_{r}^{*}=50 \mathrm{rpm}$ at $V_{d c}=$ $550 \mathrm{~V}, R_{L}=16.67 \Omega$, and $\beta=\beta_{o}$. For the same set of parameters, the measured results for $\omega_{r}^{*}=$ $2000 \mathrm{rpm}$ are plotted in Figure 16 and the results exhibit satisfactory sensorless controlled characteristics. In addition, accurately estimated $\hat{\theta}_{r}$, close current, and speed command tracking behavior can be observed.
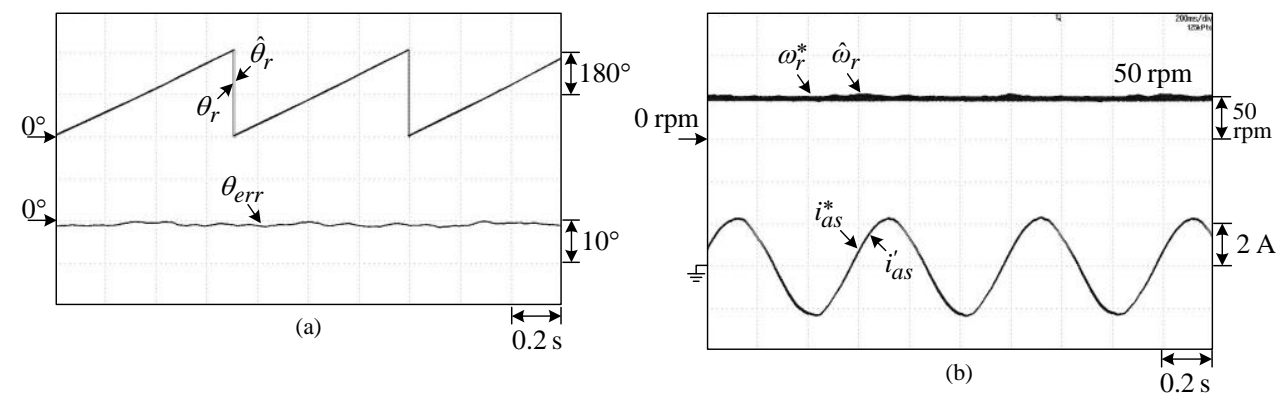

Figure 15 Measured steady-state characteristics of the developed sensorless EV SynRM drive for $\widehat{\omega}_{r}=50 \mathrm{rpm}, V_{d c}=550 \mathrm{~V}, R_{L}=16.67 \Omega$, and $\beta=\beta_{o}$. (a) measured time variation for $\theta_{r}, \hat{\theta}_{r}$, and $\theta_{e r r}$, and (b) the corresponding variation for $\left(\omega_{r}^{*}, \widehat{\omega}_{r}\right)$ and $\left(i_{a s}^{*}, i_{a s}^{\prime}\right)$.
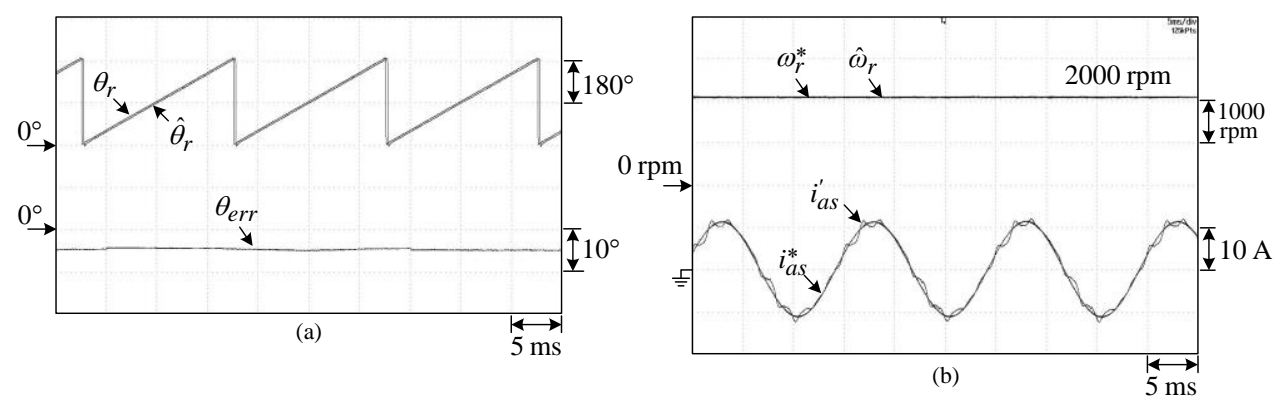

Figure 16 Measured steady-state characteristics of the developed sensorless EV SynRM drive for $\widehat{\omega}_{r}=2000 \mathrm{rpm}, V_{d c}=550 \mathrm{~V}, R_{L}=16.67 \Omega$, and $\beta=\beta_{o}$. (a) results for $\theta_{r}, \hat{\theta}_{r}$, and $\theta_{e r r}$ and $(\mathrm{b})$ results for $\left(\omega_{r}^{*}, \widehat{\omega}_{r}\right)$ and $\left(i_{a s}^{*}, i_{a s}^{\prime}\right)$. 


\subsubsection{Dynamic Response}

Figure 17(a) show the measured speed tracking response of the developed EV drive by PI control without and with SRECC for a speed command change of $\Delta \omega_{r}^{*}=100 \mathrm{rpm}$ at $\omega_{r}^{*}=$ $1900 \mathrm{rpm}, V_{d c}=550 \mathrm{~V}, R_{L}=33.9 \Omega$, and $\beta=\beta_{o}$. Figure $17(\mathrm{~b})$ shows the measured results corresponding to a step resistance change of $R_{L}=51 \Omega \rightarrow 33.9 \Omega$ and $\omega_{r}^{*}=2000 \mathrm{rpm}, V_{d c}=$ $550 \mathrm{~V}, R_{L}=51 \Omega$, and $\beta=\beta_{o}$. The results indicate good tracking and regulation dynamic response and the effectiveness of applying the robust control.
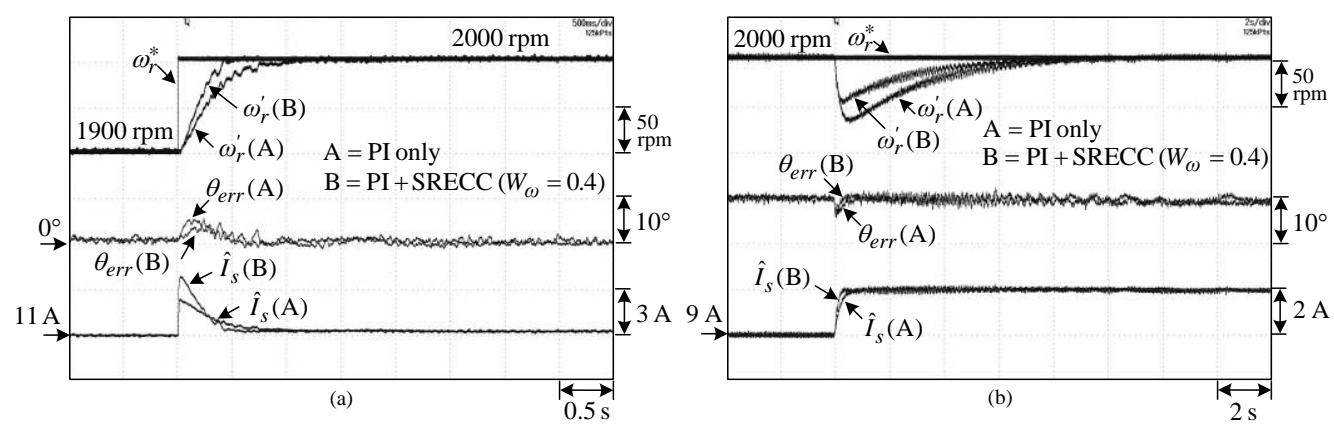

Figure 17 Measured values of $\left(\omega_{r}^{*}, \widehat{\omega}_{r}\right), \theta_{\text {err }}$, and $\hat{I}_{s}$ of the established EV SynRM drive corresponding to (a) a step speed command change of $100 \mathrm{rpm}$ and $\omega_{r}^{*}=$ $1900 \mathrm{rpm}, V_{d c}=550 \mathrm{~V}, R_{L}=33.9 \Omega$, and $\beta=\beta_{o}$ and (b) a step load resistance change $R_{L}=50.1 \Omega \rightarrow 33.9 \Omega$ at $\omega_{r}^{*}=2000 \mathrm{rpm}, V_{d c}=550 \mathrm{~V}, R_{L}=51 \Omega$, and $\beta=$ $\beta_{o}$.

\subsubsection{Acceleration/Deceleration and Reversible Operations}

Initially, the motor is stably operated at $\omega_{r}^{*}=2000 \mathrm{rpm}, V_{d c}=550 \mathrm{~V}, R_{L}=25 \Omega$, and $\beta=$ $\beta_{o}$. Now let the ramp speed command change be set to $\omega_{r}^{*}=2000 \mathrm{rpm} \rightarrow 0 \rightarrow-2000 \mathrm{rpm}$ with the falling rate of $100 \mathrm{rpm} / \mathrm{s}$. The measured values of $\left(\theta_{r}, \hat{\theta}_{r}\right)$ and $\left(\omega_{r}^{*}, \widehat{\omega}_{r}, \hat{I}_{s}\right)$ for these settings are plotted in Figure 18.
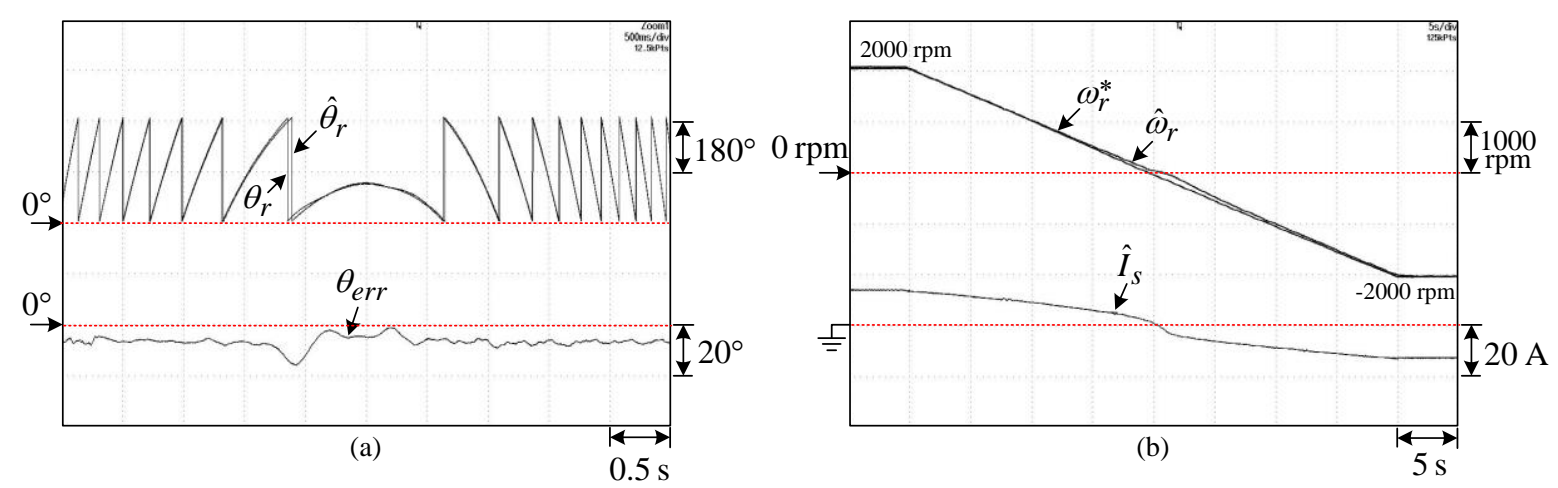

Figure 18 Measured results of the established sensorless EV SynRM drive at $V_{d c}=$ $550 \mathrm{~V}, R_{L}=25 \Omega$, and $\beta=\beta_{o}$ for the ramp command change of $\omega_{r}^{*}=2000 \mathrm{rpm} \rightarrow$ $0 \rightarrow-2000 \mathrm{rpm}$. (a) measured values of $\left(\theta_{r}, \hat{\theta}_{r}\right)$ and $\theta_{\text {err }}$, and (b) measured values of $\omega_{r}^{*}, \widehat{\omega}_{r}$, and $\hat{I}_{s}$. 
Let the reversible speed command be set to $\omega_{r}^{*}=0 \rightarrow 2000 \mathrm{rpm} \rightarrow-2000 \mathrm{rpm} \rightarrow 0 \mathrm{rpm}$ with a changing rate of $100 \mathrm{rpm} / \mathrm{s}$. The measured values of $\left(\omega_{r}^{*}, \widehat{\omega}_{r}\right), \hat{I}_{s}$, and $\theta_{\text {err }}$ at $V_{d c}=550 \mathrm{~V}, R_{L}=$ $25 \Omega$, and $\beta=\beta_{o}$ are presented in Figure 19. From the results, it can be seen that the characteristics of smooth speed reversible operation and good speed tracking are preserved by the developed SynRM drive.

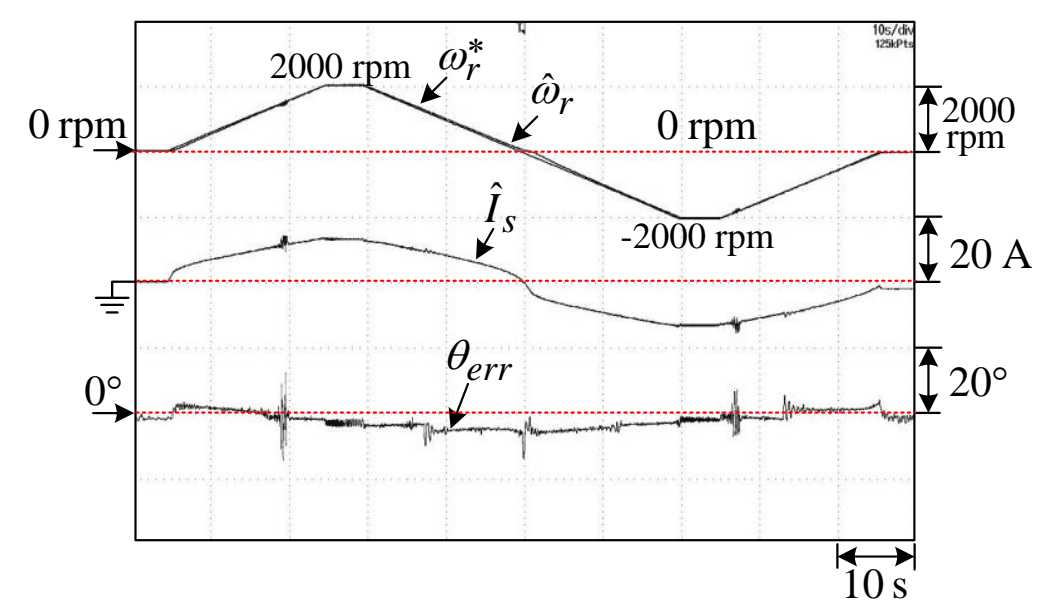

Figure 19 Measured values of $\left(\omega_{r}^{*}, \widehat{\omega}_{r}\right), \hat{I}_{s}$, and $\theta_{\text {err }}$ of the established sensorless EV SynRM drive at $V_{d c}=550 \mathrm{~V}, R_{L}=25 \Omega$, and $\beta=\beta_{o}$ for the ramp command change in the order $\omega_{r}^{*}=0 \rightarrow 2000 \mathrm{rpm} \rightarrow-2000 \mathrm{rpm} \rightarrow 0 \mathrm{rpm}$.

\subsubsection{Regenerative Braking}

Since the total moment of inertia of the established SynRM drive is not sufficiently large, the maximum speed is increased to $2500 \mathrm{rpm}$ when applying regenerative braking. The SynRM drive is stably operated at $V_{d c}=550 \mathrm{~V}, R_{L}=150 \Omega, \beta=\beta_{o}$, and $\omega_{r}^{*}=2500 \mathrm{rpm}$ and Figures 20(a) and 20 (b) show the measured values of $\left(\left(\omega_{r}^{*}, \omega_{r}^{\prime}\right), \hat{I}_{s}\right)$ and $\left(v_{b}, v_{d c}, i_{b}\right)$ for a ramp speed command change with a deceleration rate of $500 \mathrm{rpm} / \mathrm{s}$. The negative value of $i_{b}$ verifies the successful implementation of the regenerative braking operation.
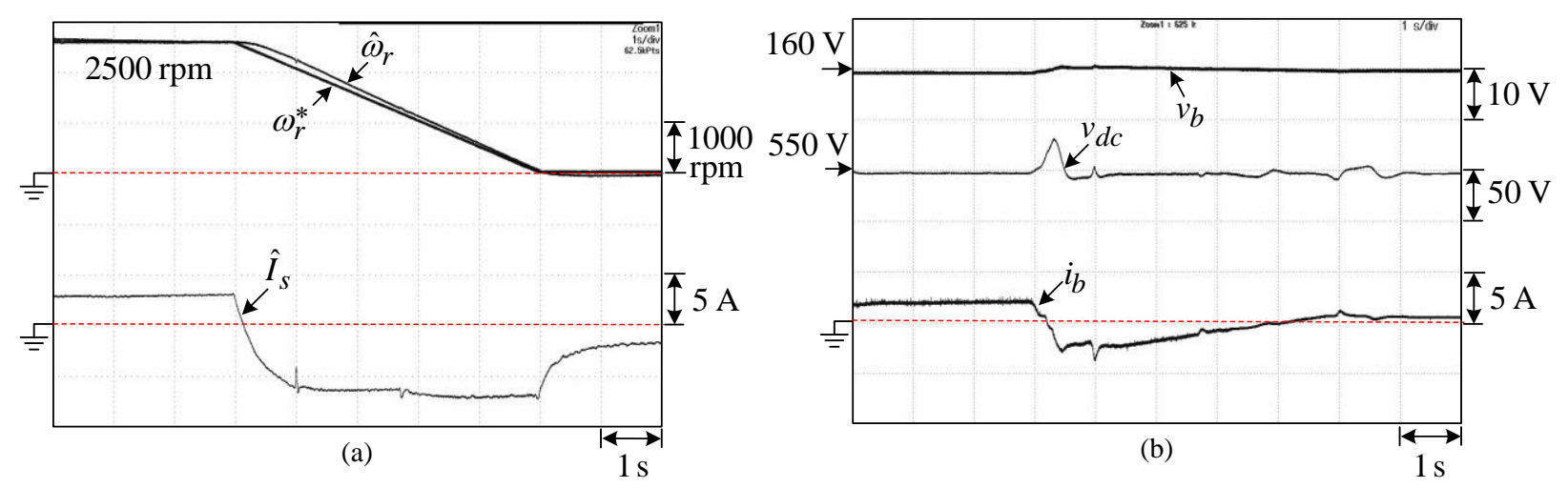

Figure 20 Measured results of the sensorless EV SynRM drive for a ramp speed command change from $2500 \mathrm{rpm}$ with the deceleration rate of $500 \mathrm{rpm} / \mathrm{s}$ at $V_{d c}=$ $550 \mathrm{~V}, R_{L}=150 \Omega$, and $\beta=\beta_{o}$. (a) measured values for $\left(\omega_{r}^{*}, \omega_{r}^{\prime}\right)$ and $\hat{I}_{s}$, and (b) measured values for $v_{b}, v_{d c}$, and $i_{b}$. 


\subsubsection{ECE15 Speed Pattern}

The measured results of the developed sensorless EV SynRM drive under the programmed ECE15 speed pattern for $\beta=\beta_{o}$ (the results for $\beta=45^{\circ}$ have been neglected here) are shown in Figure 21 (a) and the corresponding energy consumption of the battery in the two cases of $\beta=\beta_{o}$ and $\beta=$ $45^{\circ}$ are compared in Figure $21(\mathrm{~b})$. The results show that by applying $\beta=\beta_{o}$, less energy is consumed.

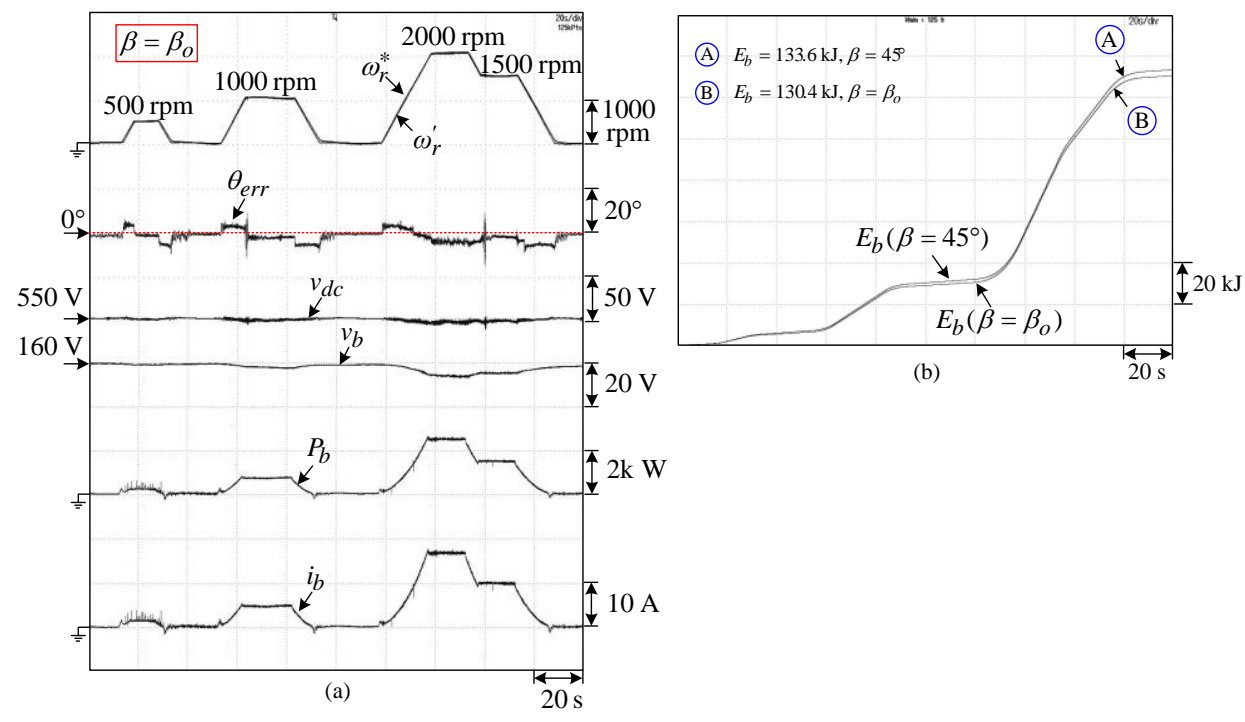

Figure 21 Efficiency assessment for the developed q-axis infected HFI sensorless SynRM drive. (a) measured values of $\omega_{r}^{*}, \omega_{r}^{\prime}, v_{d c}, v_{b}, \mathrm{i}_{\mathrm{b}}$, and $P_{b}$ for a programmed ECE15 speed pattern with a changing rate of $100 \mathrm{rpm} / \mathrm{s}$ at $R_{L}=25 \Omega$ and $\beta=\beta_{o}$. (b) $E_{b}=$ $\int P_{b} d t$ corresponding to $\beta=45^{\circ}$ and $\beta=\beta_{o}$ corresponding to the same ECE15 speed pattern.

\subsubsection{Efficiency Assessment}

For the same condition, i.e., $V_{d c}=550 \mathrm{~V}, R_{L}=16.67 \Omega$, and $\beta=\beta_{o}$, the measured steadystate characteristics of the established sensorless EV SynRM drive and the standard drive are compared in Table 1 for various speeds. The efficiencies are defined as: $\eta_{m g} \equiv P_{g} / P_{m}, \eta_{m} \equiv \sqrt{\eta_{m g}}$. As can be seen from the table, the efficiencies of the position sensorless SynRM drive are comparable to those of the standard SynRM drive.

Table 1 Measured powers and efficiencies of the HFI position sensorless SynRM drive and the standard drive at $V_{d c}=550 \mathrm{~V}, R_{L}=16.67 \Omega$, and $\beta=\beta_{o}$ for various speeds.

\begin{tabular}{llllll}
\hline Speed $(\mathrm{rpm})$ & & 500 & 1000 & 1500 & 2000 \\
\hline \multirow{4}{*}{ Sensorless } & $P_{m}(\mathrm{~W})$ & 254 & 895 & 1885.90 & 3193.35 \\
drive & $P_{g}(\mathrm{~W})$ & 183 & 719 & 1575 & 2717 \\
& $\eta_{m g}(\%)$ & 72.047 & 80.335 & 83.515 & 85.079 \\
Standard & $\eta_{m}(\%)$ & 84.88 & 89.629 & 91.386 & 92.238 \\
\hline
\end{tabular}




\begin{tabular}{llllll}
\hline drive & $P_{g}(\mathrm{~W})$ & 184 & 726 & 1588 & 2729 \\
& $\eta_{m g}(\%)$ & 72.44 & 80.85 & 84.07 & 85.55 \\
& $\eta_{m}(\%)$ & 84.947 & 89.916 & 91.689 & 92.493 \\
\hline
\end{tabular}

\section{Conclusions}

This study presents a high-efficiency sensorless EV SynRM drive using a pulsating sinewave HF voltage injection. Through analytic and experimental explorations and by comparing the characteristics of the d-axis and q-axis injected HFI sensorless controlled SynRM drives, the q-axis injection was adopted. Experimental observations indicated that the $d$-axis injected mechanism could not be operated stably above a certain load level. Hence, only the q-axis injection mechanism was tested further. Because of the influence of speed-and load-dependent slot harmonic effects on the sensorless control behavior, the changed injection frequency with rotor speed was proposed. The slotting effects were also considered in the current controller design. It was shown that the EV SynRM drive can be operated under wider speed and heavier load ranges with the designed feedback and robust controllers. To achieve maximum efficiency, ACS was applied to conduct a proper commutation shift of SynRM. The measured results indicated that the developed sensorless EV drive exhibits stable operation over a wide speed and load range, and the EV drive exhibits good driving performance in terms of acceleration/deceleration, reversible, and regenerative braking operations. The experimental demonstration of the high energy conversion efficiencies being comparable to the standard drive was also presented in this study.

\section{Author Contributions}

G. Vijay Kumar: Main author involving the measurements and the paper writing; Min-Ze Lu: Assisting the author and doing the proofreading; Chang-Ming Liaw: Advisor, giving suggestion and revisions for research results and writing.

\section{Funding}

No organization or foundation that funded this research.

\section{Competing Interests}

The authors have declared that no competing interests exist.

\section{References}

1. Krause $P$, Wasynczuk $O$, Sudhoff $S$, Pekarek S. Analysis of electric machinery and drive systems. 3rd ed. New Jersey: John Wiley \& Sons; 2013.

2. Lipo TA. Synchronous reluctance machine - a viable alternative for AC drive. Electr Mach Power Syst. 1991; 19: 659-671.

3. Liu HC, Lee J. Optimum design of an IE4 line-start synchronous reluctance motor considering manufacturing process loss effect. IEEE Trans Ind Electron. 2018; 65: 3104-3114.

4. Hadla H, Cruz S. Predictive stator flux and load angle control of synchronous reluctance motor drives operating in a wide speed range. IEEE Trans Ind Electron. 2017; 64: 6950-6959. 
5. Vijay Kumar G, Chuang CH, Lu MZ, Liaw CM. Development of an electric vehicle synchronous reluctance motor drive. IEEE Trans Veh Technol. 2020; 69: 5012-5024.

6. Guo W, Zhao ZM, Zhang YC. Analysis and experimental study of slot effect in synchronous reluctance permanent magnet motors. Proceedings of the 5th International Power Electronics and Motion Control Conference; 2006 August 14-16; Shangai, China.

7. Villet WT, Kamper MJ. Variable-gear EV reluctance synchronous motor drives- an evaluation of rotor structures for position-sensorless control. IEEE Trans Ind Electron. 2014; 61: 5732-5740.

8. Moghaddam RR. Fundamental study on rotor eddy current losses in high frequency machines due to current harmonics. Proceedings of the IEEE Energy Conversion Congress and Exposition; 2015 September 20-24; Montreal, QC, Canada.

9. Mahmoud $\mathrm{H}$, Bianchi $\mathrm{N}$. Nonlinear analytical model of eccentric synchronous reluctance machines considering iron saturation and slotting effect. IEEE Trans Ind Appl. 2017; 53: 20072015.

10. Antonello R, Ortombina L, Tinazzi F, Zigliotto M. Advanced current control of synchronous reluctance motors. Proceedings of the 12th Power Electronics and Drive Systems; 2017 December 12-15; Honolulu, HI, USA.

11. Wiedemann S, Hall S, Kennel RM, Alakula M. Dynamic testing characterization of a synchronous reluctance machine. IEEE Trans Ind Appl. 2018; 54: 1370-1378.

12. Benjak $O$, Gerling D. Review of position estimation methods for PMSM drives without a position sensor, part III: Methods based on saliency and signal injection. Proceedings of the International Conference on Electrical Machines and Systems; 2010 October 10-13; Incheon, South Korea.

13. Sul SK, Kwon YC, Lee Y. Sensorless control of IPMSM for last 10 years and next 5 years. CES Trans Electr Mach Syst. 2017; 1: 91-99.

14. Wang G, Valla M, Solsona J. Position sensorless permanent magnet synchronous machine drives - a review. IEEE Trans Ind Electron. 2020; 67: 5830-5842.

15. Tuovinen $T$, Hinkkanen M, Harnefors L, Luomi J. Comparison of a reduced-order observer and a full-order observer for sensorless synchronous motor drives. IEEE Trans Ind Appl. 2012; 48: 1959-1967.

16. Tuovinen T, Hinkkanen M. Adaptive full-order observer with high-frequency signal injection for synchronous reluctance motor drives. IEEE Trans Emerg Sel Topics Power Electron. 2014; 2: 181-189.

17. Nguyen DQ, Loron L, Dakhouche K. High-speed sensorless control of a synchronous reluctance motor based on an extended kalman filter. Proceedings of the European Conference on Power Electronics and Applications; 2015 September 8-10; Geneva, Switzerland.

18. Ichikawa S, Tomita M, Doki S, Okuma S. Sensorless control of synchronous reluctance motors based on extended EMF models considering magnetic saturation with online parameter identification. IEEE Trans Ind Appl. 2006; 42: 1264-1274.

19. Kato K, Tomita M, Hasegawa M, Doki S, Okuma S, Kato S. Position and velocity sensorless control of synchronous reluctance motor at low speed using disturbance observer for highfrequency extended EMF. Proceedings of the 37th Annual Conference of IEEE Industrial Electronics Society; 2011 November 7-10; Melbourne, VIC, Australia.

20. Bolognani S, Ortombina L, Tinazzi F, Zigliotto M. Model sensitivity of fundamental-frequencybased position estimators for sensorless PM and reluctance synchronous motor drives. IEEE Trans Ind Electron. 2018; 65: 77-85. 
21. Kang SJ, Kim JM, Sul SK. Position sensorless control of synchronous reluctance motor using high frequency current injection. IEEE Trans Energy Convers. 1999; 14: 1271-1275.

22. Briz F, Degner MW, Diez A, Lorenz RD. Static and dynamic behavior of saturation-induced saliencies and their effect on carrier-signal-based sensorless AC drives. IEEE Trans Ind Appl. 2002; 38: 670-678.

23. Jang JH, Ha Jl, Ohto M, Idle K, Sul SK. Analysis of permanent-magnet machine for sensorless control based on high-frequency signal injection. IEEE Trans Ind Appl. 2004; 40: 1595-1604.

24. Guerrero JM, Leetmaa M, Briz F, Zamarron A, Lorenz RD. Inverter nonlinearity effects in highfrequency signal-injection- based sensorless control methods. IEEE Trans Ind Appl. 2005; 41: 618-626.

25. Kock HW, Kamper MJ, Kennel RM. Anisotropy comparison of reluctance and PM synchronous machines for position sensorless control using HF carrier injection. IEEE Trans Power Electron. 2009; 24: 1905-1913.

26. Agarlita SC, Boldea I, Blaabjerg F. High-frequency injection-assisted active-flux- based sensorless vector control of reluctance synchronous motors, with experiments from zero speed. IEEE Trans Ind Appl. 2012; 48: 1931-1939.

27. Yousefi-Talouki A, Pescetto P, Pellegrino G, Boldea I. Combined active flux and high-frequency injection methods for sensorless direct-flux vector control of synchronous reluctance machines. IEEE Trans Power Electron. 2018; 33: 2447-2457.

28. Andreescu GD, Schlezinger C. Enhancement sensorless control system for PMSM drives using square-wave signal injection. Proceedings of the SPEEDAM; 2010 June 14-16; Pisa, Italy.

29. Yoon YD, Sul SK, Morimoto S, Ide K. High bandwidth sensorless algorithm for AC machines based on square-wave-type voltage injection. IEEE Trans Ind Appl. 2011; 47: 1361-1370.

30. Park NC, Kim SH. Simple sensorless algorithm for interior permanent magnet synchronous motors based on high-frequency voltage injection method. IET Elect Power Appl. 2014; 8: 6875.

31. Kim D, Kwon YC, Sul SK, Kim JH, Yu RS. Suppression of injection voltage disturbance for highfrequency square-wave injection sensorless drive with regulation of induced high-frequency current ripple. IEEE Trans Ind Appl. 2016; 53: 302-312.

32. Varatharajan A, Pellegrino G. Sensorless synchronous reluctance motor drives: A general adaptive projective vector approach position estimation. IEEE Trans Ind Appl. 2020; 56: 14951504.

33. Kojima T, Suzuki T, Hazeyama M, Kayano S. Position sensorless control of synchronous reluctance machines based on magnetic saturation depending on current phase angles. IEEE Trans Ind Appl. 2020; 56: 2171-2179. 
JEPT 2021; 3(3), doi:10.21926/jept.2103037

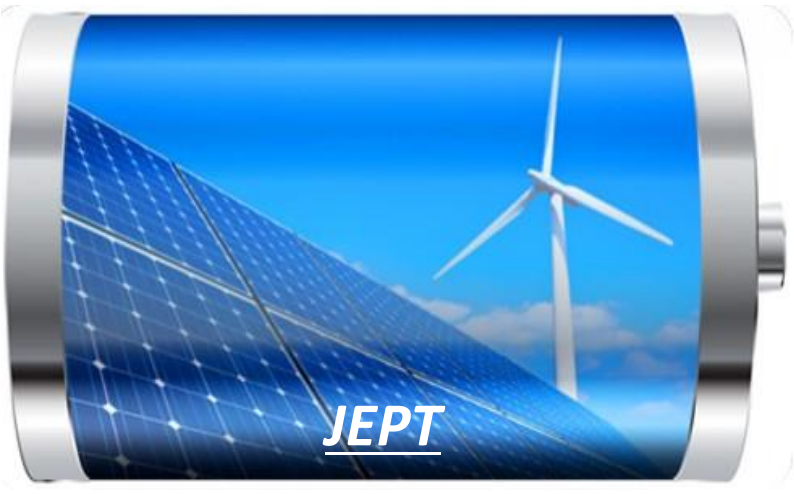

Enjoy JEPT by:

1. Submitting a manuscript

2. Joining in volunteer reviewer bank

3. Joining Editorial Board

4. Guest editing a special issue

For more details, please visit:

http://www.lidsen.com/journal/jept 